\title{
Overview With Results and Lessons Learned of the X-43A Mach 10 Flight
}

\author{
Laurie A. Marshall, ${ }^{*}$ Catherine Bahm, ${ }^{\dagger}$ and Griffin P. Corpening ${ }^{\ddagger}$ \\ NASA Dryden Flight Research Center, Edwards, California, 93523-0273, USA \\ Robert Sherrill ${ }^{\S}$ \\ NASA Langley Research Center, Hampton, Virginia, 23681-2199, USA
}

This paper provides an overview of the final flight of the NASA X-43A project. The project consisted of three flights, two planned for Mach 7 and one for Mach 10. The third and final flight, November 16, 2004, was the first Mach 10 flight demonstration of an airframe-integrated, scramjet-powered, hypersonic vehicle. The goals and objectives for the project as well as those for the third flight are presented. The configuration of the Hyper-X stack including the $\mathrm{X}-43 \mathrm{~A}$, Hyper-X launch vehicle, and Hyper-X research vehicle adapter is discussed. The second flight of the X-43A was successfully conducted on March 27, 2004. Mission differences, vehicle modifications and lessons learned from the second flight as they applied to the third flight are also discussed. An overview of flight 3 results is presented.

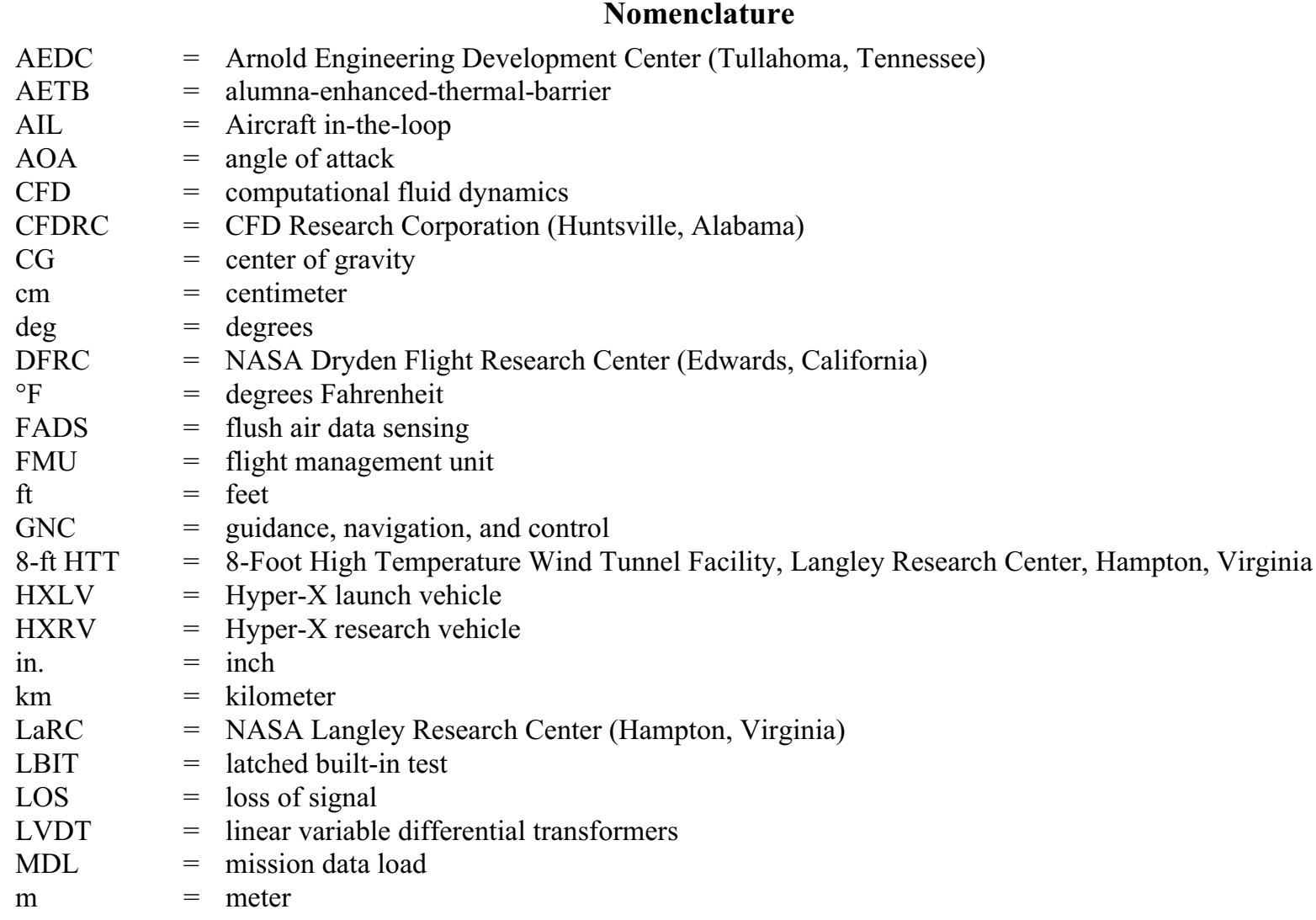

\footnotetext{
* Aerospace Engineer, Research Engineering, P.O. Box 273/Mail Stop D-2228, AIAA Member.

${ }^{\dagger}$ Aerospace Engineer, Research Engineering, P.O. Box 273/Mail Stop 4840D, AIAA Member.

* Aerospace Engineer, Research Engineering, P.O. Box 273/Mail Stop 4840H, AIAA Member.

$\S$ Aerospace Engineer, Research Engineering, Mail Stop 449, AIAA Member.
} 


\begin{tabular}{|c|c|c|}
\hline $\mathrm{m} / \mathrm{s}$ & $=$ & meter per second \\
\hline $\mathrm{ms}$ & $=$ & milliseconds \\
\hline $\mathrm{N}$ & $=$ & newton \\
\hline NAWC-WD & $=$ & Naval Air Warfare Center Weapons Division (California) \\
\hline nmi & $=$ & nautical miles \\
\hline OSC & $=$ & Orbital Sciences Corporation (Chandler, Arizona) \\
\hline P-3 & $=$ & Navy Orion Aircraft (data acquiring aircraft) \\
\hline $\mathrm{Pa}$ & $=$ & pascal \\
\hline PID & $=$ & parameter identification \\
\hline psi & $=$ & pounds per square inch \\
\hline PSC & $=$ & propulsion system controller \\
\hline $\operatorname{psf}^{n}$ & $=$ & pounds per square foot \\
\hline PST & $=$ & Pacific Standard Time \\
\hline q & $=$ & dynamic pressure \\
\hline RTD & $=$ & resistance temperature detectors \\
\hline RV & $=$ & research vehicle \\
\hline S & $=$ & second \\
\hline TPS & $=$ & Thermal Protection System \\
\hline TUFI & $=$ & toughened unipiece fibrous insulation \\
\hline
\end{tabular}

\section{Introduction}

$\mathrm{T}$

HE goal of the Hyper-X program was to demonstrate and validate the technology, the experimental techniques, and the computation methods and tools for design and performance predictions of a hypersonic aircraft with an airframe-integrated, scramjet propulsion system. Three X-43A airframe-integrated, scramjet research vehicles were designed and fabricated to achieve that goal by flight test, two test flights at Mach 7 and one test flight at Mach $10 .{ }^{1}$ The Mach 10 vehicle is shown in Fig. 1. The partners in this multiorganization project were NASA Langley Research Center (LaRC), NASA Dryden Flight Research Center (DFRC), Alliant Techsystems, Inc. (ATK GASL), Orbital Sciences Corporation, and Boeing (Seal Beach, California). NASA was responsible and the lead for (1) the research vehicle design (lines), (2)aerodynamic and propulsion wind tunnel testing and CFD to support flight test risk reduction, (3)the aerodynamic and propulsion databases, (4)flight simulation, (5)vehicle validation and verification testing, (6)vehicle integration, (7)flight preparation, and (8)flight testing. ATK GASL and Boeing were responsible for the development and fabrication of the X-43A or Hyper-X research vehicle (HXRV) and the research vehicle (RV) adapter. Orbital Sciences Corporation (OSC) in Chandler, Arizona was responsible for the design, development, fabrication, and test of the Hyper-X launch vehicle (HXLV).

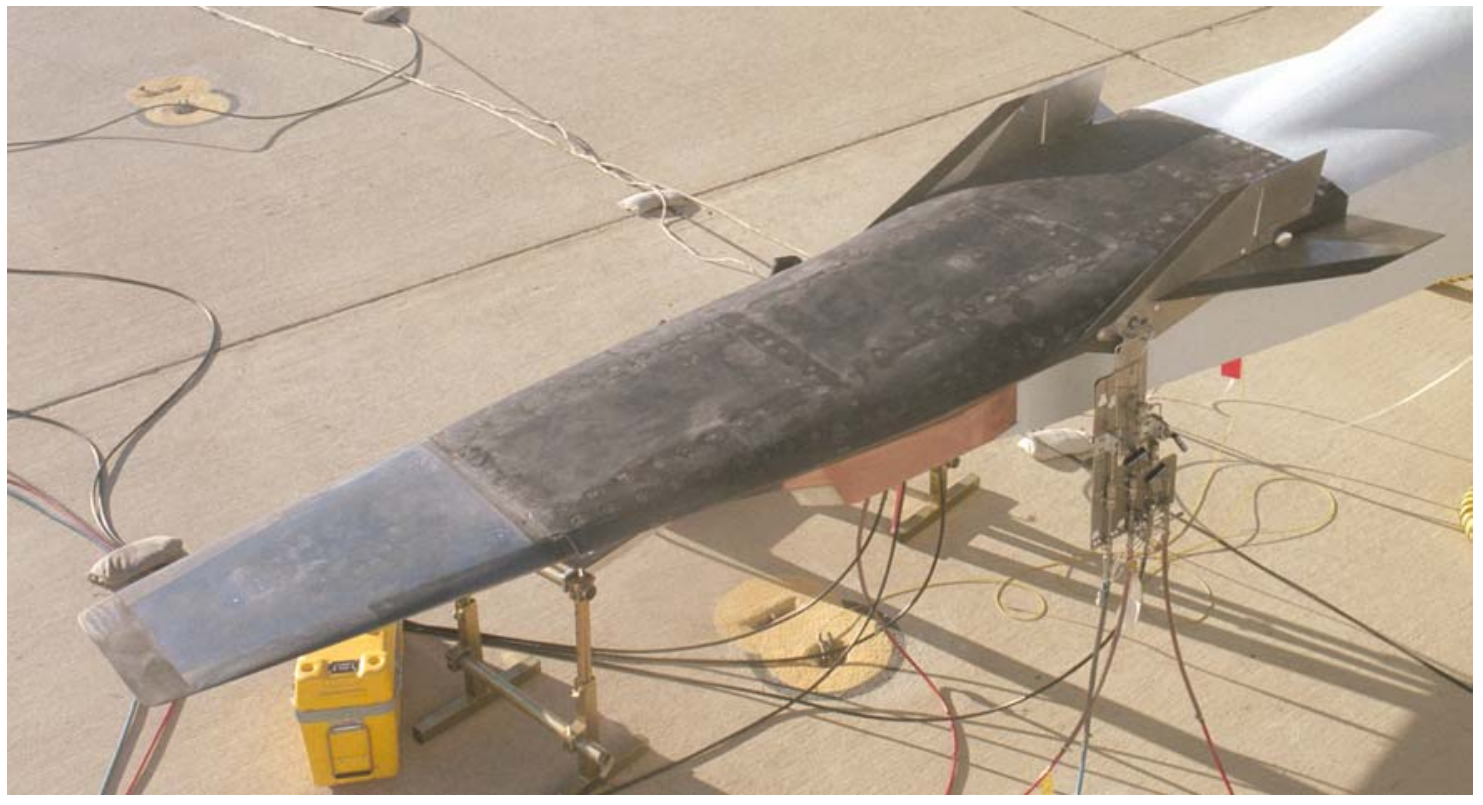

Figure 1. The X-43A ship 3 in final preparation for flight. 
A modified first-stage Pegasus ${ }^{\circledR}$ booster, launched the Hyper-X research vehicle to the test conditions. The modified Pegasus first stage mated to the HXRV by a research vehicle adapter is known as the Hyper-X launch vehicle (HXLV) or "Hyper-X stack," which was air-launched from the NASA B-52B carrier aircraft in the Naval Air Warfare Center Weapons Division (NAWC-WD) Sea Test Range off the coast of California.

The first Mach 7 flight of the X-43A was attempted on June 2, 2001 and experienced a failure during the boost phase of the mission when the HXLV departed from controlled flight. ${ }^{2}$ The second Mach 7 flight was successfully completed on March 27, 2004. ${ }^{3}$ The third and final X-43A vehicle successfully performed the Mach 10 mission on November 16, 2004. This paper provides a technical overview of the third research vehicle and its mission, including the roles, responsibilities, and results of the engineering disciplines responsible for the success of the Mach 10 flight. Lessons learned and insights into the impact of some project decisions are also presented.

\section{Mission Description}

The X-43A mission consisted of four flight phases: B-52 Carried Flight, HXLV Boost, HXRV Separation, and HXRV Free Flight. Both the engine test and vehicle descent occurred during the HXRV Free Flight phase. Flights originated at NASA DFRC at Edwards Air Force Base in California. Figure 2 depicts the Hyper-X Mach 10 mission profile. The NASA B-52B, tail number 008, carried the Hyper-X stack to the designated launch point, Mach 0.8 at an altitude of 40,000 $\mathrm{ft}(12,192 \mathrm{~m})$, approximately $50 \mathrm{nmi}(92.6 \mathrm{Km})$ off the southern California coast where the stack was released. Five seconds after launch from the B-52, the HXLV booster ignited and carried the X-43A along a predetermined trajectory to the designated separation conditions. Following booster burnout, the X-43A was separated from the RV adapter by four explosive bolts and two pyrotechnically pressurized pistons to begin the free-flight phase and scramjet engine experiment. Approximately 2.5 seconds after separation the HXRV engine cowl door opened to obtain 3 seconds of fuel-off performance baseline data. The engine then ignited and operated for approximately 10 seconds. Following engine operation the HXRV obtained an additional 6 seconds of fuel-off performance data before the cowl door was commanded closed. Following the engine test sequence, the X-43A performed a recovery maneuver to begin the controlled predetermined descent trajectory to low subsonic speed. During the descent, parameter identification and frequency sweep maneuvers were performed to assess aerodynamic performance and open loop frequency response. The X-43A splashed down beyond the NAWC-WD Sea Test Range in the open ocean and was not recovered.

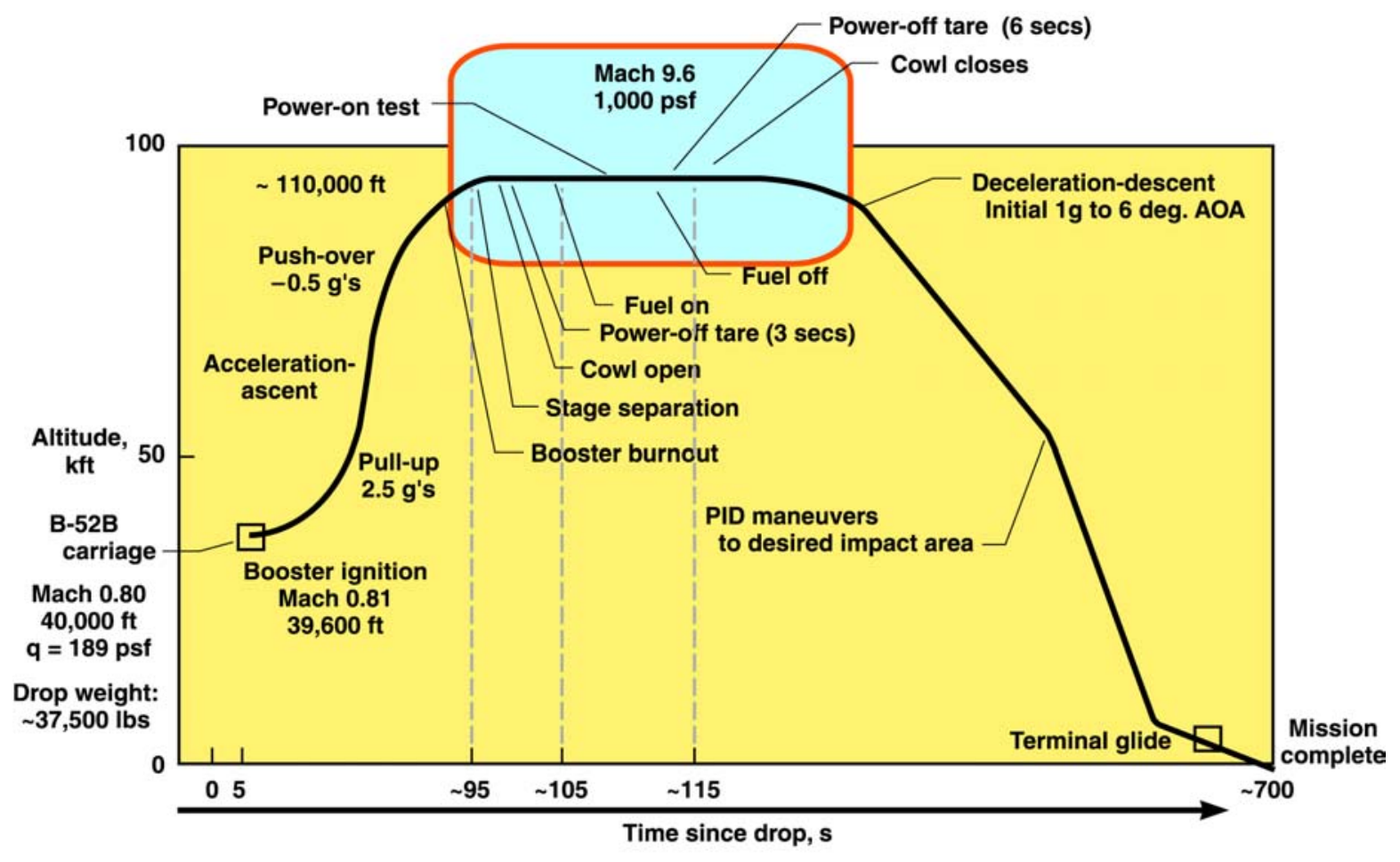

Figure 2. Mach 10 mission profile. 


\section{Mission Objectives}

The primary objective of the X-43A project was to demonstrate the performance of an airframe-integrated, scramjet-powered vehicle at selected test conditions. Data were acquired to verify scramjet, aerodynamics, and stability and control performance predictions as well as to perform flight correlation of the ground-based experimental data. In addition, data were acquired to verify the hypersonic vehicle structural integrity and system design. The minimum success criteria for flight were to successfully complete the mission through the fueled and unfueled portions of the scramjet engine experiment and to obtain data. Additional research objectives included: vehicle acceleration during the scramjet propulsion experiment and obtaining X-43A aerodynamic, structural, and guidance, navigation, and control (GNC) data until splash.

\section{Vehicle Description}

The X-43A vehicle was approximately 12 feet $(3.66 \mathrm{~m})$ long, 5 feet $(1.52 \mathrm{~m})$ wide, 2 feet $(0.61 \mathrm{~m})$ high, and weighed approximately 3000 pounds (13,345 N). Figure 3 shows both the external (Fig. 3(a)) and internal (Fig. 3(b)) vehicle configuration. The X-43A was powered by a hydrogen-fueled, airframe-integrated scramjet propulsion system. The engine uses gaseous silane ( $\mathrm{SiH} 4)$ as the ignition source for the hydrogen fuel. In order to prevent oxygen intrusion within the vehicle, nitrogen gas was used to maintain an inert environment and to pressurize the $\mathrm{X}-43 \mathrm{~A}$ internal cavities. The nitrogen gas was stored in tanks in the RV adapter for use during boost and within the $\mathrm{X}-43 \mathrm{~A}$ for use during the engine test. The high heat loads experienced during these portions of the flight, required that the engine leading edges be kept cool. The stored nitrogen gas was also used as a coolant pressurant to move coolant to the engine leading edges. An ethylene glycol-water mixture in the RV adapter served as the coolant during boost, while water only, located in the HXRV, was used as coolant during the engine test.

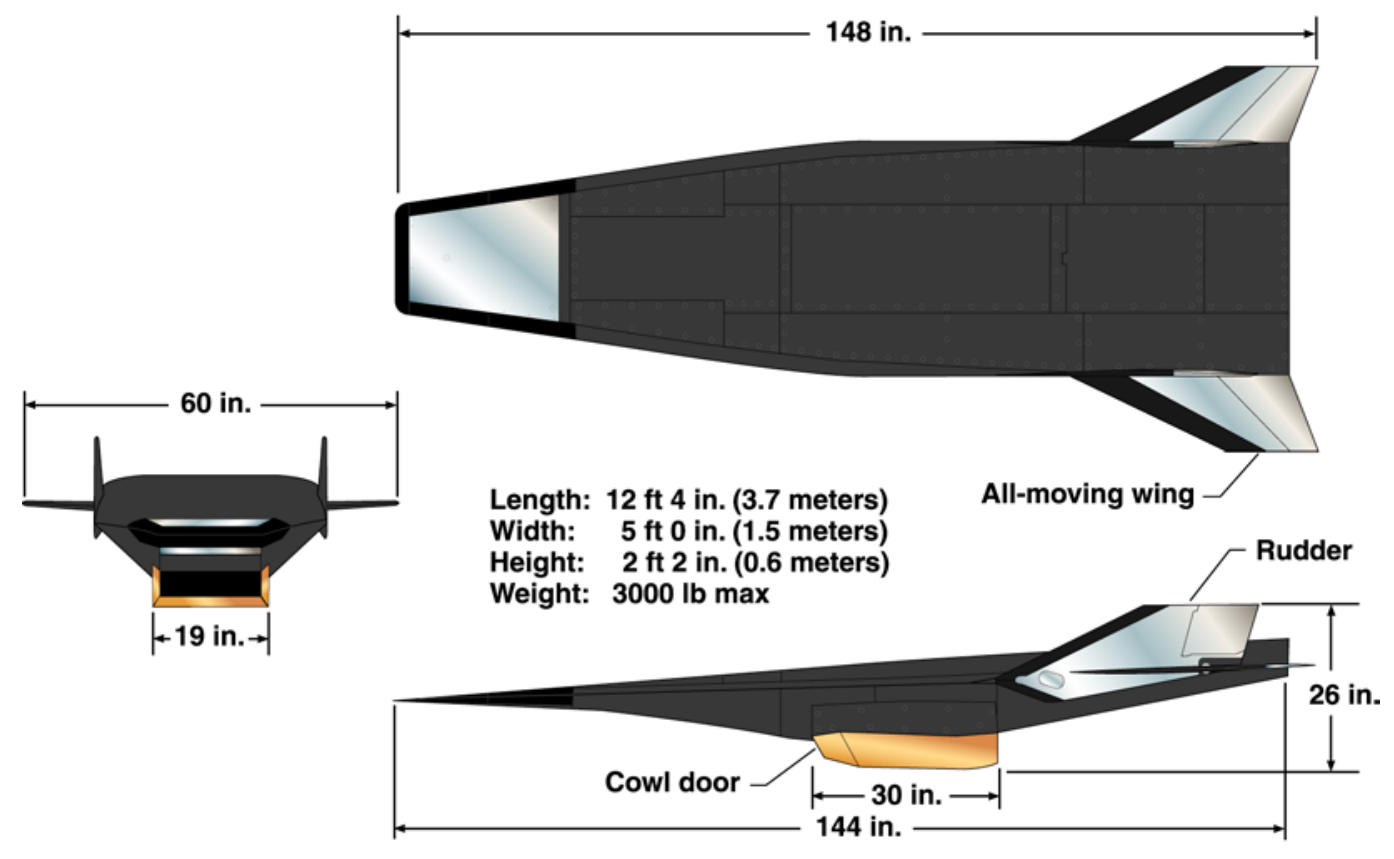

a) External.

Figure 3. The $X-43 A$ vehicle configuration. 


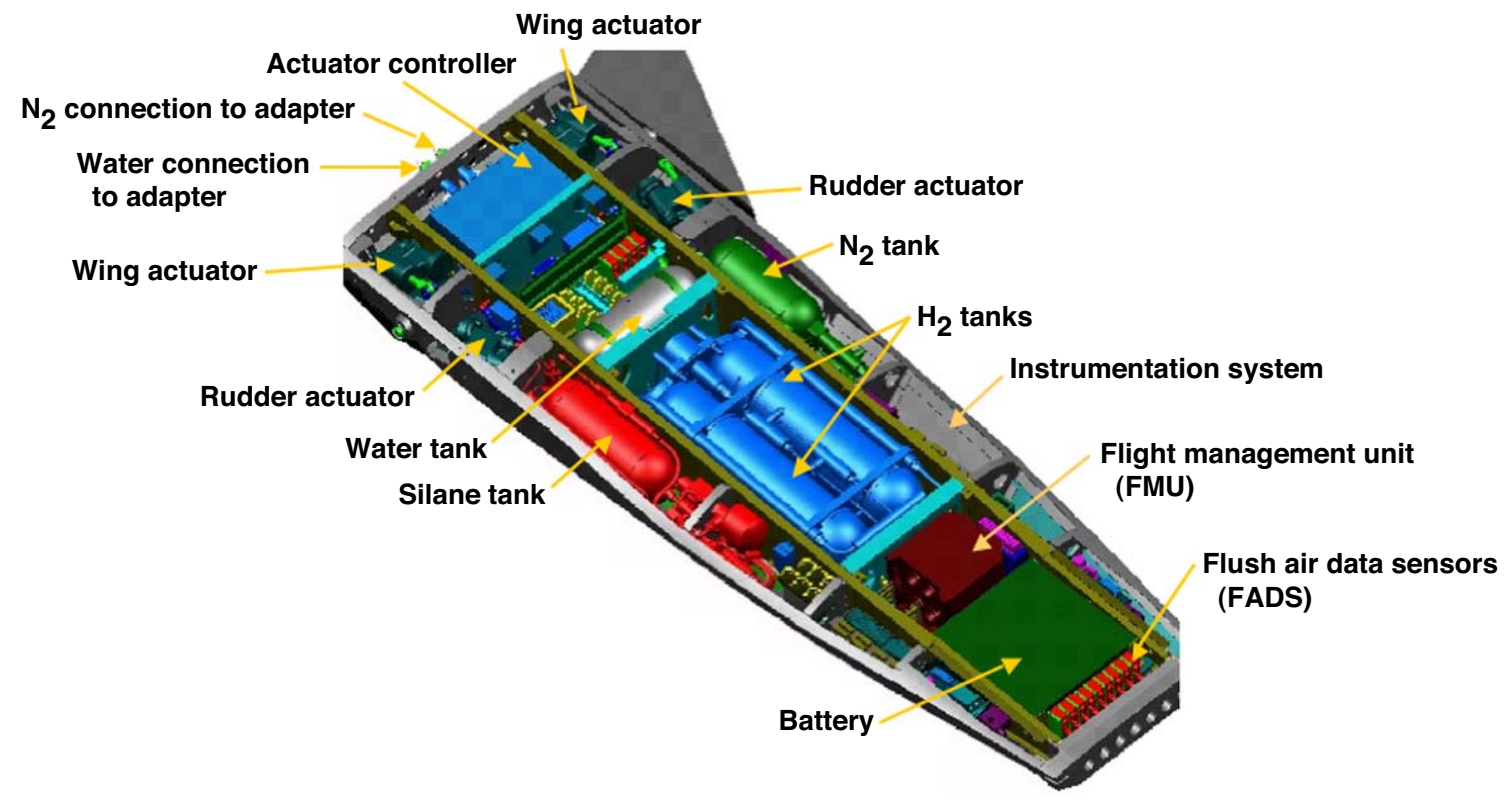

b) Internal.

Figure 3. Concluded.

\section{A. Management and Control Systems and Material Layout}

The vehicle management and control systems included five electromechanical actuators, controlled by a single electromagnetic actuator controller (Fig. 3(b)) and a flight management unit (FMU). The actuators operate two all-moving wings, two rudders, and the cowl door (not pictured). The FMU integrates the functions of navigation, flight control sensors, and mission computer into one unit.

The vehicle material layout is shown in Fig. 4. The airframe is primarily a steel and aluminum structure protected by alumina-enhanced-thermal-barrier (AETB) tiles coated with toughened unipiece fibrous insulation (TUFI). The edges around the nose and control surface leading edges are carbon-carbon composites. The control surfaces are Haynes alloy and the nose is made of tungsten. The engine is constructed primarily of a copper alloy and has water-cooled leading edges. 


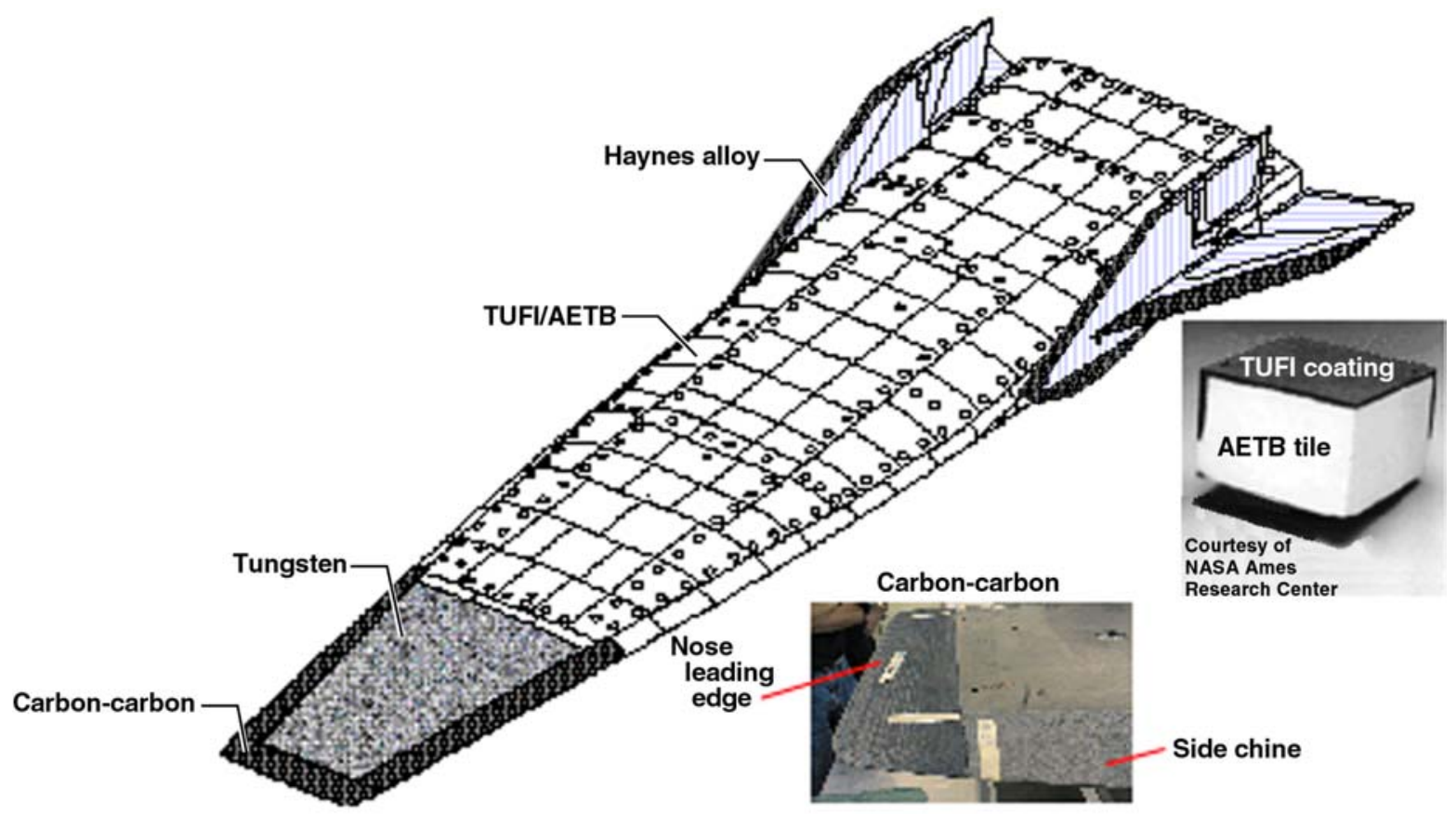

Figure 4. Vehicle material layout.

\section{B. Instrumentation System}

The instrumentation system used for data acquisition was comprised of the sensors, wires, connectors, electronics, and software necessary to acquire and transmit data from the HXRV to both airborne and ground-based receiving sites for recording and real-time monitoring. The X-43A flights travel past the range for data acquisition from the ground based assets. As a result, data receiving aircraft were required to supplement ground information and this allows capture of data for the entire flight.

Prior to launch from the B-52, to determine if the vehicle was ready for launch, the data from the instrumentation system was used to monitor and evaluate the vehicle systems health. The X-43A vehicle instrumentation system sensors consisted of pressure transducers, strain gages, thermocouples, and resistance temperature detectors (RTD). In addition, there were miscellaneous analog measurements from electrolytic oxygen sensors, inductive current sensors, and voltage dividers, as well as serial data from the FMU via a 1553 data bus interface. A list of the sensors used, organized by measurement type is shown in table 1 .

Table 1. Instrumentation summary.

\begin{tabular}{lrr}
\hline \hline \multicolumn{1}{c}{ Measurement type } & HXRV & \\
\hline Embedded time code & 6 & \\
Pressures & 175 & \\
Strain gages & 15 & \\
Temperatures & 128 & \\
Miscellaneous analog & 13 & \\
1553 data bus (450 16-bit words) & 788 & (unique parameters) \\
\hline Total & 1125 & \\
\hline \hline
\end{tabular}




\section{Flight 3 Approach and Philosophy}

Flight 3 preparations began in the summer of 2003, in the form of a schedule to flight. It was desired that the third flight be completed by the end of September 2004. This was an aggressive schedule; especially considering that the preparation of the second vehicle was a two-year effort. As a result of the serial nature of the X-43A project and the availability of the project team, a majority of the flight 3 preparation work could not begin until flight 2 was complete. The second X-43A flight was successfully completed on March 27, 2004. At this time, a September 2004 flight date would require final models, i.e. aerodynamics, propulsion, mass properties, and fuel systems, to be delivered in early April 2004. If a model delivery date slipped, it would be extremely difficult to maintain the September goal.

In order to accomplish the flight 3 schedule, changes had to be made to the project team approach and philosophy. Some of the decisions about the flight 3 approach were easily made. The project team would have to remain largely intact. Unlike flight 2 preparations, very little duplicative or independent analysis would be performed. Emphasis for the flight 3 preparation effort would be on the primary portion of the mission, i.e. boost, separation, and the engine test through cowl closed. The descent portion of the mission would be worked on an as-time-is-available basis. The decision with regard to flight 2 data analysis represented the major technical deviation from the original project plan. Flight 2 data was analyzed for approximately 1 month. Based on this limited review of the data the flight 3 models would not be updated to incorporate the flight 2 results. Another project level decision pertained to data acquisition. In order to capture data for an entire X-43A flight (Mach 7 or Mach 10), it was necessary to use data acquiring aircraft. The aircraft chosen for this task was a Navy NP-3D Orion aircraft (P-3). Preflight predictions indicated that the Mach 10 X-43A would travel further downrange in flight than the Mach 7 vehicle. As a result, two data acquiring aircraft would be required to capture the entire flight. Unfortunately, because of the P-3 maintenance schedule, only one was available to support the Mach 10 flight. It was decided that the aircraft would be positioned such that it would capture the primary mission (boost through cowl closed) and capture as much data prior to splashdown as possible, since it would not also be able to capture the X-43A splash point.

\section{Comparison of Flight 3 and Flight 2}

The X-43A flights targeted two key flight conditions for the scramjet powered vehicle: Mach 7 and Mach $10{ }^{4}$ While the mission was in general the same, the two flights had different requirements and required updates and modifications to the hardware and software.

\section{A. Requirement Differences}

The primary requirement changes between the two missions were for the separation and the engine test. Early predictions of the HXLV capabilities for the Mach 10 flight had the separation Mach number set at 10.07 with a dynamic pressure of $1090 \mathrm{psf}(52.19 \mathrm{kPa})$. Increases in the Hyper-X stack weight and aerodynamic drag, and modifications to the trajectory to account for vehicle stability concerns reduced the HXLV performance and separation Mach number to 9.6. Since the X-43A was not able to significantly change the Mach number and dynamic pressure in the short time between separation and the engine test, the engine test conditions for these parameters were dependent on HXLV performance and separation conditions. Risk assessment and trade studies were conducted to assess the impact of the reduction in separation Mach number on HXRV scramjet engine performance. The risk assessment analysis looked at shock location, peak heating rate, and vehicle axial acceleration as a function of Mach number, angle of attack, and dynamic pressure. The trade studies focused on modifying the HXLV trajectory Mach number, dynamic pressure, and flight path angle parameters. The result of these studies allowed relaxation in the dynamic pressure and flight path angle requirements. The final flight 3 separation requirements are specified in table 2 . The requirements listed in the table are defined such that the HXRV would be within the area where there was a high likelihood of meeting the objectives of the scramjet experiment.

The X-43A engine test requirements were specified in terms of the angles of attack and sideslip. During the engine test the HXRV had to maintain zero degrees of sideslip within an acceptable tolerance. At cowl open the nominal angle of attack requirement was 1 degree, which had to be maintained within an acceptable tolerance from cowl open through cowl closed, except during transient events which consisted of cowl open, engine ignition, engine unstart, and engine off. The HXRV had to be able to autonomously control to these engine test requirements. 
Table 2. Separation requirements.

\begin{tabular}{ll}
\hline \hline \multicolumn{1}{c}{ Parameter } & \multicolumn{1}{c}{ Target } \\
\hline Mach number (GRAM 95) & $9.6^{*}$ \\
Dynamic pressure (GRAM 95) & $1000 \mathrm{psf}^{*}$ \\
Angle of attack & $0.0 \mathrm{deg}$ \\
Angle of sideslip & $0.0 \mathrm{deg}$ \\
Flightpath angle & $1.5 \mathrm{deg}$ \\
\hline \hline
\end{tabular}

*Flight 3 requirement changes.

\section{B. Hardware Differences}

Although most of the flight 2 vehicle systems remain unchanged for flight 3 , the more demanding flight conditions for the Mach 10 mission required some changes to the vehicle hardware. The physical differences between the Mach 7 vehicle and the Mach 10 vehicle were contained in: the outer mold line, the engine flowpath, the vehicle mass properties, and the thermal protection system. Hardware modifications and some software modifications are shown in Fig. 5. As a result of the predicted increased aerodynamic heating, the vehicle 3 vertical tails were solid Haynes alloy as opposed to the Haynes alloy skins and rib structure of vehicle 2. Although the vehicle 3 thermal protection system (TPS) still consisted of AETB tiles and carbon-carbon leading edges on the wings and around the nose, carbon-carbon was also included on the leading edges of the vertical tails. The carbon-carbon pieces located on the leading edges of the nose, wings, and vertical tails were also treated with a hafnium carbide coating in addition to the silicon carbide coating used on vehicle 2 . The engine external TPS was enhanced with a thicker zirconium layer on the engine lower surface.

Additional research instrumentation was added to the Mach 10 engine. This instrumentation consisted of two skin friction and two heat flux sensors. The skin friction sensors measured engine wall sheer stress; the heat flux sensors measured engine wall heat transfer rate. Also unique to the Mach 10 vehicle instrumentation were high-temperature strain gages located in a pocketed attachment area in the left vertical tail.

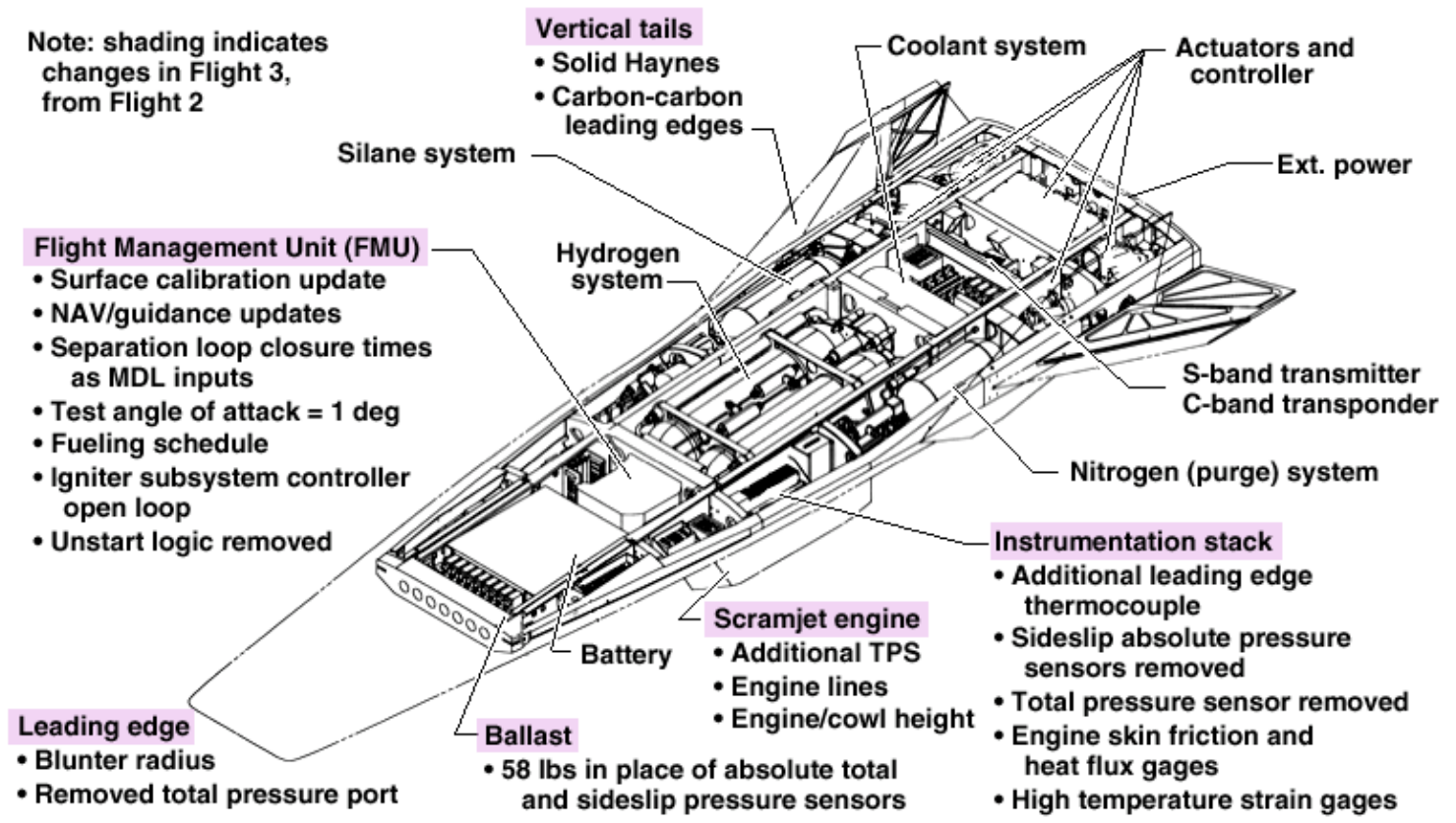

Figure 5. The X-43A modification summary. 


\section{Software Differences}

Although there were some hardware modifications between vehicles two and three, a large portion of time during the flight 3 effort was spent in the normal process flow of flight software development. This process includes: developing models and uncertainties, incorporating them into the simulation, performing the subsequent analyses, and ultimately developing new flight software. Unlike the two Mach 7 missions, where the same control laws were used for both, the Mach 10 mission required a new design. In addition to flight controls, the flight software included updates to: guidance, descent maneuvers, flight 3-specific surface calibrations, test angle of attack, igniter subsystem controller and fueling schedule.

\section{Flight 3 Preparation Challenges}

The focus of the project team shifted to flight 3 in May 2004. At this time, a majority of the flight 2 analysis was complete, development of flight 3 models was under way and the HXRV, RV adapter, and HXLV hardware processing was proceeding normally. The aggressive flight 3 schedule was success oriented and assumed no major difficulties. However, as with any major project, technical issues developed that had the potential to impact the schedule to flight. In addition to these, there were some known challenges resulting from both programmatic decisions and the Mach 10 flight conditions that also had to be addressed and overcome.

\section{A. Reduced Mach 10 Stage Separation Wind Tunnel Test Data}

Flight 2 separation had been successful, however the aerodynamic database had been derived in a large part from a very extensive full-interference stage separation wind tunnel test performed at the Arnold Engineering Development Center (AEDC). The wind tunnel test had been very costly and time consuming, so prior to flight 2 it was decided that this test would not be performed for flight 3 . As a result additional methods were required to develop the aerodynamic database. Existing wind tunnel test data were utilized in parallel with flight 2 unsteady computational fluid dynamics (CFD) capabilities to assess Mach 7 to Mach 10 scaling issues. The CFD work performed by CFD Research Corporation (CFDRC) used a FASTRAN code with coupled trajectory integration that allowed relative motion of the RV adapter and the HXRV. The CFD research work performed in preparation for flight 2 showed good agreement between CFDRC predicted aerodynamic forces and moments, and separation aerodynamic database values at similar conditions. After flight 2, a similar analysis was performed comparing flight 2 data to the CFDRC predicted forces and moments also showed good agreement. These results provided further validation and confidence in the flight 3 separation aerodynamics approach.

\section{B. Limited Mach 10 Propulsion Ground Test Data}

Similar to the lack of high fidelity separation wind tunnel test data for the third flight, there was also less data available from scramjet wind tunnel tests. In preparation for the Mach 7 flight, a full-scale X-43A vehicle engine and lower surface was mounted in the NASA Langley 8-Foot High Temperature Tunnel (8-ft HTT). During that test, the full engine experiment was conducted and various fueling schedules were explored. Force and moment data were obtained that demonstrated how the vehicle would behave at selected throttle settings. Unfortunately, the high energy requirement for the Mach 10 mission flight conditions prohibited such a test being performed. Shock tunnel testing was the only viable option. Data was obtained from two tunnel facilities: The NASA Hypersonic Pulse Facility (HYPULSE) at ATK-GASL and the Army LENS shock tunnel at CalSpan (Buffalo, New York). Both were operated in the reflected shock tunnel mode for the Mach 10 tests. Unlike the 8-ft HTT test performed for the Mach 7 mission where the full duration engine test sequence $(20 \mathrm{~s})$ was conducted, test times in the HYPULSE and LENS facilities were 2 to $3 \mathrm{~ms}$ and $12 \mathrm{~ms}$ respectively. These short test times allowed only single performance points per run, so unlike the 8-ft HTT test, no testing of fuel schedule or cowl position transitions were possible. The uncertainties in the propulsion database were increased to account for the reduced ground test data for the various conditions during the engine test.

\section{Leading Edge Radius Erosion}

In preparation for the Mach 10 mission, several high-temperature heating wind tunnel tests were performed in which the carbon-carbon material, design, coatings, and placement were determined. Arc jet tests were performed on vehicle 3 carbon-carbon test samples in the $\mathrm{H} 2$ facility at AEDC. Results from these tests showed ablation of the carbon-carbon nose leading edge at heating conditions and durations more severe than the planned flight trajectory. Even though these conditions were not likely to be experienced in flight, it was decided to design and machine a new nosepiece that would incorporate a larger leading edge radius, reducing the likelihood of material ablation. This modification also required an alteration to the upper outer mold line to prevent a change to the nose planform. 


\section{HXRV Axial Center of Gravity}

Results from the mass properties weight and balance assessment for the X-43A indicated that the axial center of gravity $(\mathrm{CG})$ was 0.51 inches $(1.29 \mathrm{~cm})$ aft of the allowable limit. Fifty-eight pounds $(258 \mathrm{~N})$ of ballast were required to bring the $\mathrm{CG}$ forward to within the requirements. However, the X-43A was a very tightly packed vehicle with no spare room for ballast. It was decided that the absolute pressure sensors used for total pressure and angle of sideslip measurement in the research flush air data sensing (FADS) system would be removed and replaced with tungsten ballast. The FADS system used both absolute and differential pressures to determine sideslip angle. Preliminary flight 2 analysis indicated that the more sensitive differential pressure measurements were more beneficial in determining sideslip than the absolute pressure sensors. Therefore, removing the absolute pressure sensors on flight 3 would have very little impact on the calculation of sideslip. The sensors were removed and the ballast installed. No software modifications were necessary, since the resultant vehicle CG was within the specified requirement.

\section{E. Ignitor Subsystem Controller}

The purpose of the propulsion system controller (PSC) was to control the fuel delivery to the engine, minimize the risk of unstart or flameout, and to command the engine cowl door movement. Early flight 3 PSC testing identified a problem with the ignitor subsystem controller. During the test, when the hydrogen fuel schedule was initiated the system venturi meter became unchoked. As a result, the PSC reverted to an open loop mode during the ignitor flow rate schedule, which caused a nonsteady ignitor mass flow rate. Although the system was designed to go open loop if the two internal mass flow rate calculations disagreed, the known resultant nonsteady transient was not desirable as a baseline if it could be prevented. To prevent the scramjet from experiencing the nonsteady mass flow rate transient in-flight, the PSC was modified with an open-loop ignitor subsystem controller as a baseline, i.e. the ignitor subsystem controller was always open loop. After the modifications were included in the flight software, the PSC testing was repeated. The results indicated that the modifications had the desired effect on the PSC.

\section{F. Heat Exchanger}

The HXRV hydrogen fuel system employed an in-line heat exchanger to assure proper gas temperature for engine operation. A heat exchanger was used instead of a direct tank heater to maximize the amount of fuel supplied to the scramjet during the engine test. The fuel systems underwent regular leak and functional testing as part of the normal vehicle preparation process. Integrated leak and functional testing results showed unacceptable leak rates in the hydrogen system motorized control valve, which controls hydrogen flow rates to the engine. An inspection of the valve revealed that contamination was the cause. Corrosion of the heat exchanger was identified as the source of the contamination. As a result a new heat exchanger was manufactured and installed in the fuel system. The new heat exchanger was kept inert with positive pressure helium gas to reduce the possibility of oxidation, corrosion, or contamination occurring. Subsequent leak and functional testing demonstrated that the system was leak tight with acceptable particulate levels.

\section{G. Carbon-Carbon Delamination}

During a fit check and inspection of the carbon-carbon chines around the tungsten nose, delamination of a section of the right forward chine was observed. The carbon-carbon pieces went through several heat treatment cycles during the manufacturing process. Since all the carbon-carbon pieces went through these processes, there was concern that this was not an isolated incident. A replacement chine was fabricated and special attention was given during the manufacturing process. Moreover, all the carbon-carbon pieces, including the new chine, underwent tap testing and thermographic inspection to ensure all pieces were intact.

\section{H. HXRV Left-Rudder-Wing-Contact Incident}

The close proximity of the HXRV rudders and wings required extra care when moving them past the range of normal operation. Wing heating analyses, indicated that the left wing root would need to be trimmed to provide a sufficient gap between the wing and the fuselage to account for the predicted thermal expansion. In order to gain access to the wing root, the left wing was rotated past the normal operating range. While returning the left wing to zero after the wing trim operation was complete, the left rudder and left wing came in contact. As a result of the contact, small dents were present in the wing and rudder surface at the point of contact and the rudder was visibly offset from zero. A damage assessment team determined that the respective actuators and controller were not stressed beyond existing qualification loads. Even though the rudder spindle was somewhat damaged, the analysis showed significant margin remained on the rudder spindle to successfully perform the mission with a high degree of confidence. Therefore, replacement of the rudder spindle was not necessary. The left rudder and left wing were recalibrated and the flight software was updated with the new calibrations to remove the offset in the rudder. 


\section{Meeting the Separation Requirements}

In developing the launch vehicle for the X-43A program, the NASA-Orbital team had to develop aerodynamic models and guidance strategies precise enough to deliver the X-43A research vehicle to meet test conditions at which the scramjet was designed to operate. This challenge was significant because of the inherent total impulse uncertainties associated with large solid rocket motors, normal atmospheric variations, and flight testing where no data existed for the highly unusual booster and X-43A configuration. To account for this, extensive uncertainty models were developed, which allowed for conservative estimations on performance. This challenge had existed for the Mach 7 flight also, but the precision of the as flown Mach 7 flight trajectory and separation results provided confidence in this approach.

\section{Overview of Results}

The flight test results presented provide an overview of the Mach 10 mission from launch to splash. These results serve as an introduction to the analyses performed by the specific engineering disciplines including aerodynamics, propulsion, GNC, systems, instrumentation, and structures.

\section{A. Boost}

The Mach 10 flight of the X-43A began at 14:34 PST with a successful launch from the B-52B, tail number 008, on November 16, 2004. Motor ignition occurred as planned 5 seconds after launch. During the boost the HXLV maintained nominal attitude closely following the predicted boost trajectory. The RV adapter fluid systems performed as expected with the coolant and pressurant initiated 43 seconds into the boost to supply coolant to the scramjet engine and purge to the X-43A internal cavities. ${ }^{5}$ The highest loads the X-43A wings experienced during the primary portion of the mission occurred during boost in the push-over maneuver to negative angle of attack as expected. Figure 6 shows the X-43A wing hinge moments and surface positions for the first 50 seconds during boost when the actuator brake was engaged. Eighty-eight seconds after launch from the B-52, the HXLV delivered the $\mathrm{X}-43 \mathrm{~A}$ to the predetermined separation conditions. Table 3 demonstrates how close these conditions were to the predicted separation conditions. In most cases the flight separation conditions were within 1-sigma of the target.
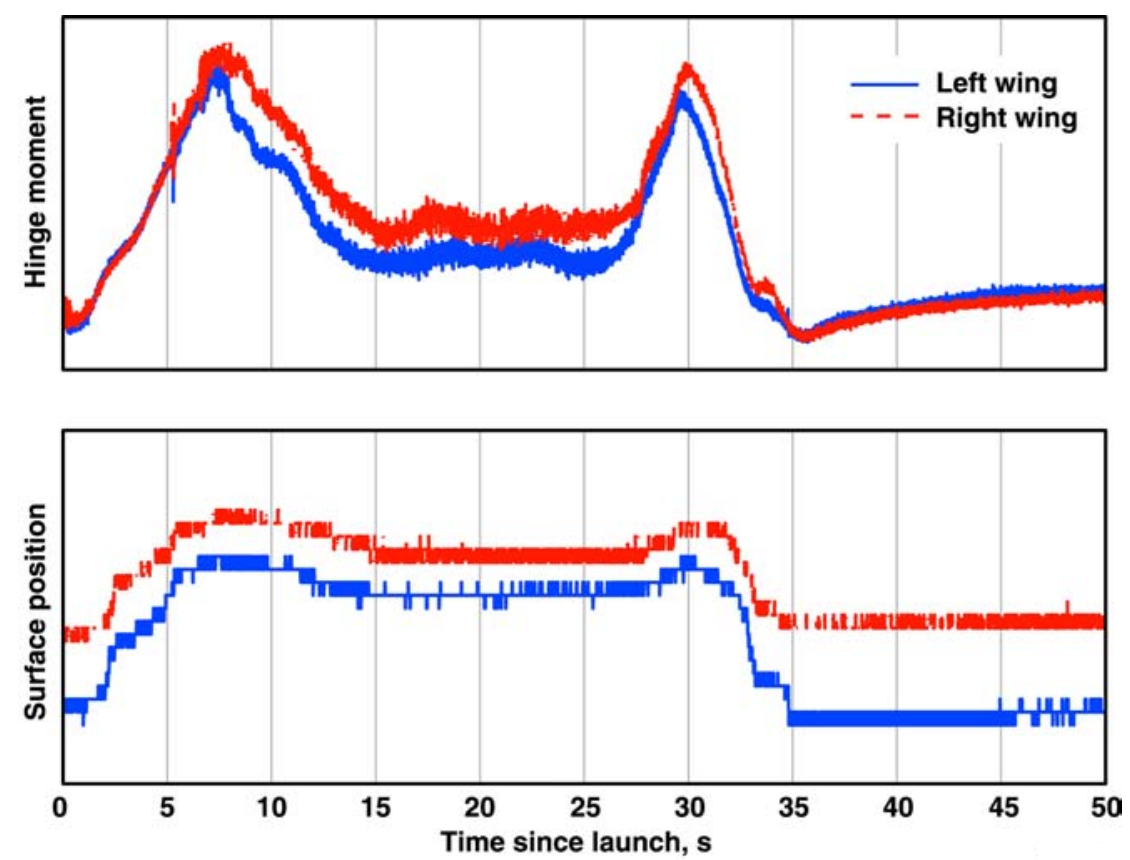

Figure 6. The $X-43 A$ wing hinge moments and positions. 
Table 3. Separation condition results.

\begin{tabular}{lccc}
\hline \hline \multicolumn{1}{c}{ Parameter } & Target & $\begin{array}{c}\text { Flight no. } 3 \\
\text { values }\end{array}$ & Deviation \\
\hline Time to condition & $\leq 104.0 \mathrm{~s}$ & $88.16 \mathrm{~s}$ & \\
Altitude & $109,580 \mathrm{ft}$ & $109,440 \mathrm{ft}$ & $-140 \mathrm{ft}$ \\
Mach* & 9.6 & 9.736 & 0.136 \\
Dynamic pressure* & $1,000 \mathrm{psf}$ & $959 \mathrm{psf}$ & $-41.0 \mathrm{psf}$ \\
Flightpath elevation angle & $1.5 \mathrm{deg}$ & $1.69 \mathrm{deg}$ & $+0.19 \mathrm{deg}$ \\
Booster angle of attack & $0.0 \mathrm{deg}$ & $0.08 \mathrm{deg}$ & $+0.08 \mathrm{deg}$ \\
Booster sideslip angle & $0.0 \mathrm{deg}$ & $-0.13 \mathrm{deg}$ & $-0.13 \mathrm{deg}$ \\
\hline \hline
\end{tabular}

* Computed using best estimate atmospheric model.

\section{B. Separation}

Both the software separation logic and the mechanical systems functioned properly, which lead to a successful separation. The separation sequence was initiated by the "ready to separate" signal sent from the HXLV to the HXRV. Three seconds after receiving the "ready to separate" signal, the HXRV FMU sent the separate command to the HXLV. The HXLV received the separate command, activated the explosive bolts and pressurized pistons, and successfully separated the X-43A from the RV Adapter and HXLV. Figure 7 shows the performance of the port RV Adapter piston. The piston extension measured by the linear variable differential transformers (LVDT) was well within the predictions from the high fidelity separation simulation. The X-43A successfully separated from the launch vehicle and achieved stable flight. Figures 8(a) and 8(b) show images from different times during the separation event, taken by the cameras located in the RV adapter.

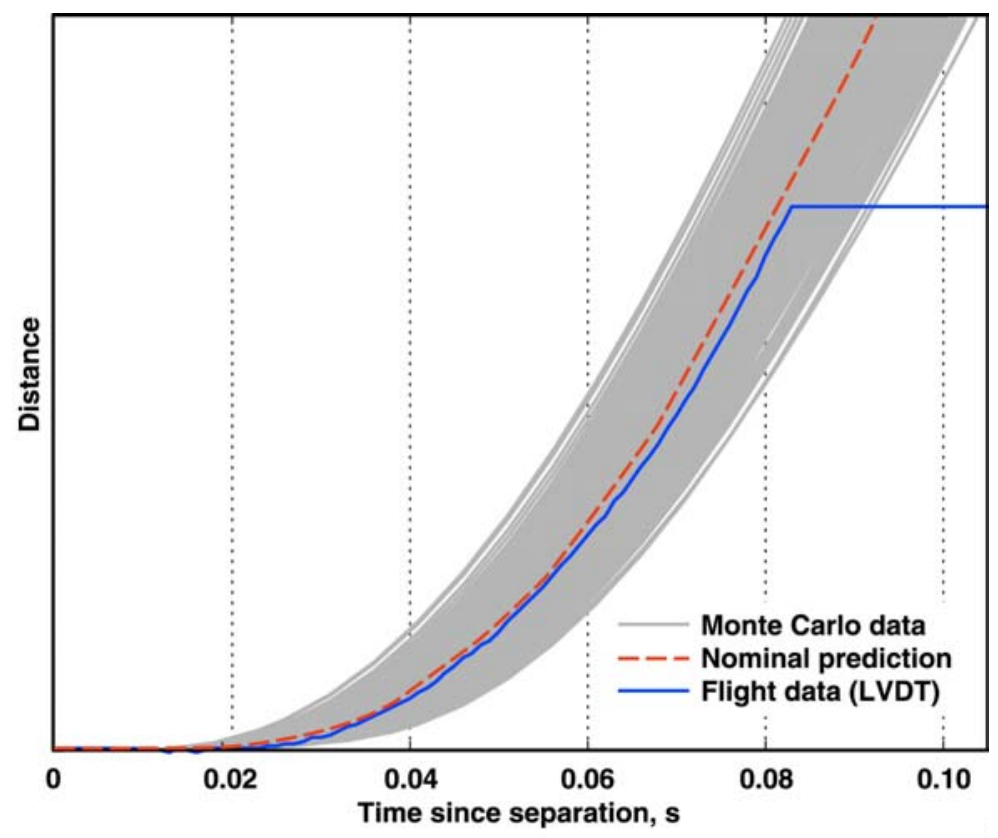

Figure 7. Port piston extension. 


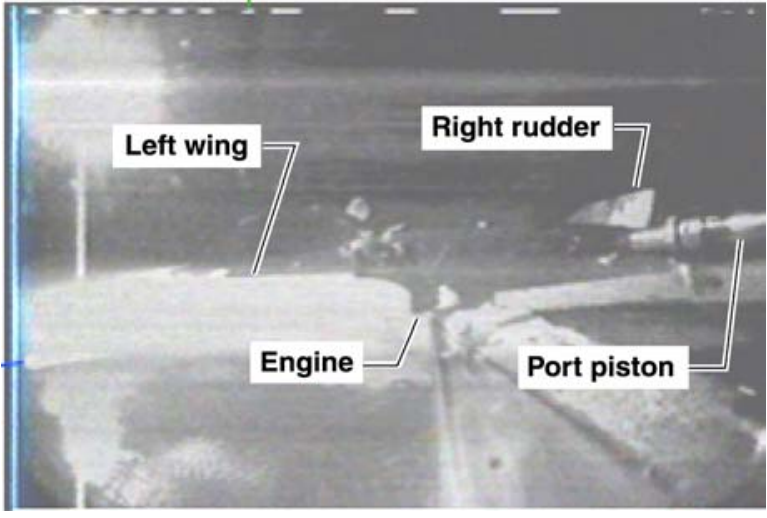

a) Left camera.

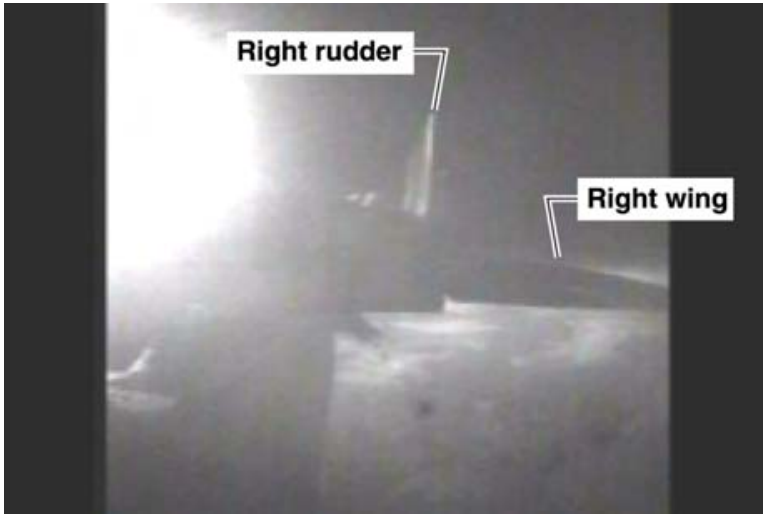

b) Right camera.

Figure 8. Adapter camera images.

\section{Engine Experiment}

The scramjet experiment began with the cowl door opening on schedule 2.5 seconds after separation. When the engine cowl door opened, the X-43A was at the predicted engine test conditions. The preexperiment tare was successfully performed and the engine fueling sequence was initiated approximately 5 seconds after separation. Both the ignitor and the fuel were delivered to the engine as predicted. The scramjet was fueled for approximately 10 seconds and provided the predicted thrust. During the time the engine was operating, the X-43A sustained thrust equal to drag, achieving a cruise condition as predicted. Figure 9 shows the approximate flight axial acceleration curve as it compared to the nominal and Monte Carlo prediction data. During powered flight, the maximum Mach number achieved was 9.68 and the X-43A flight controls maintained the desired vehicle angle of attack of 1 degree within the requirements and predictions, as shown in Fig. 10. Following the engine test, the post experiment tare was performed. Both the cowl open fuel-off preexperiment and postexperiment tare pressure data and the fuel-on engine pressure data were compared to the preflight predictions. Figure 11 shows the excellent agreement between the flight data and the predictions. These results substantiate hypersonic engine design tools and flight scaling methodologies, satisfying the primary objective of the Hyper-X program. The thermal environment was similar to what was expected, with the highest recorded temperatures occurring on the nose, as predicted. Figure 12 shows the flight data from one of the thermocouples located in the carbon-carbon nosepiece as compared to the predictions from the thermal model for the nearest nodes fore and aft to the location of that same thermocouple. The engine experiment and the primary portion of the mission were concluded when the cowl door closed 22 seconds after separation. 


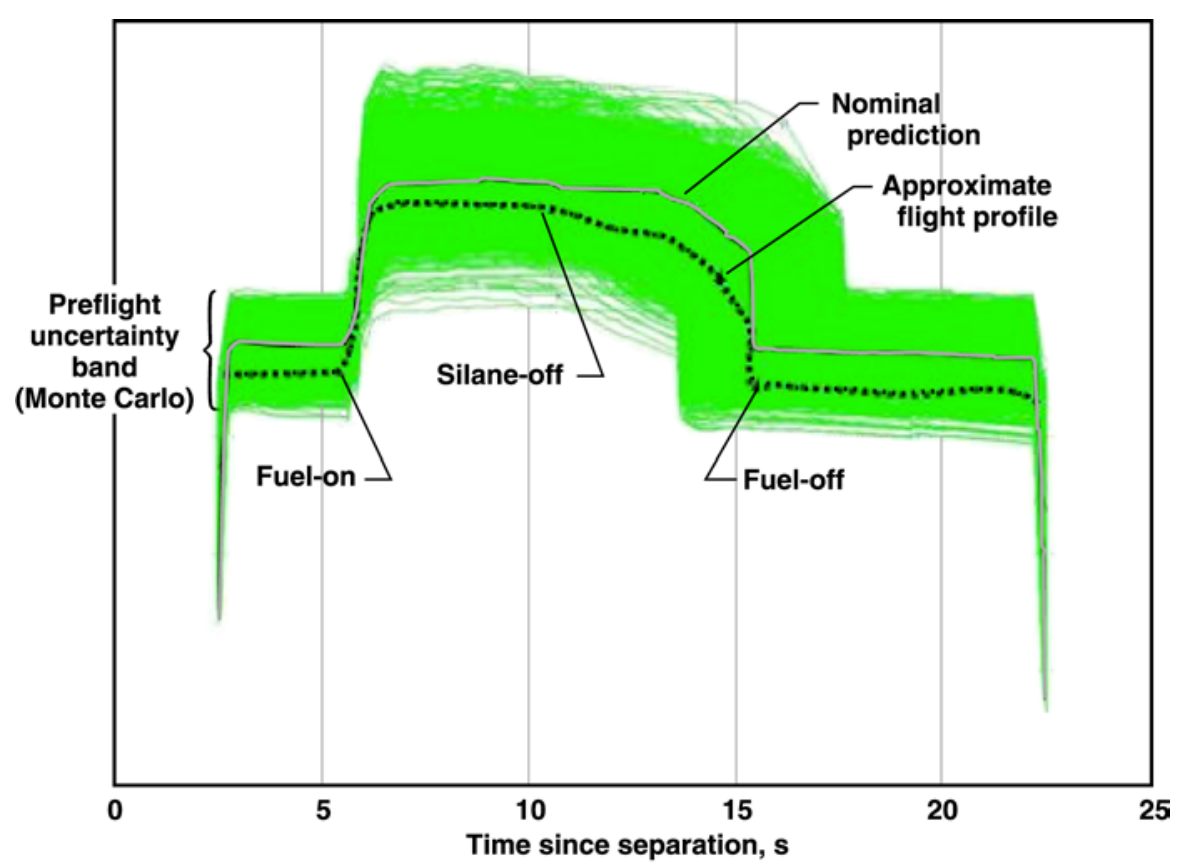

Figure 9. Axial acceleration profile during engine test.

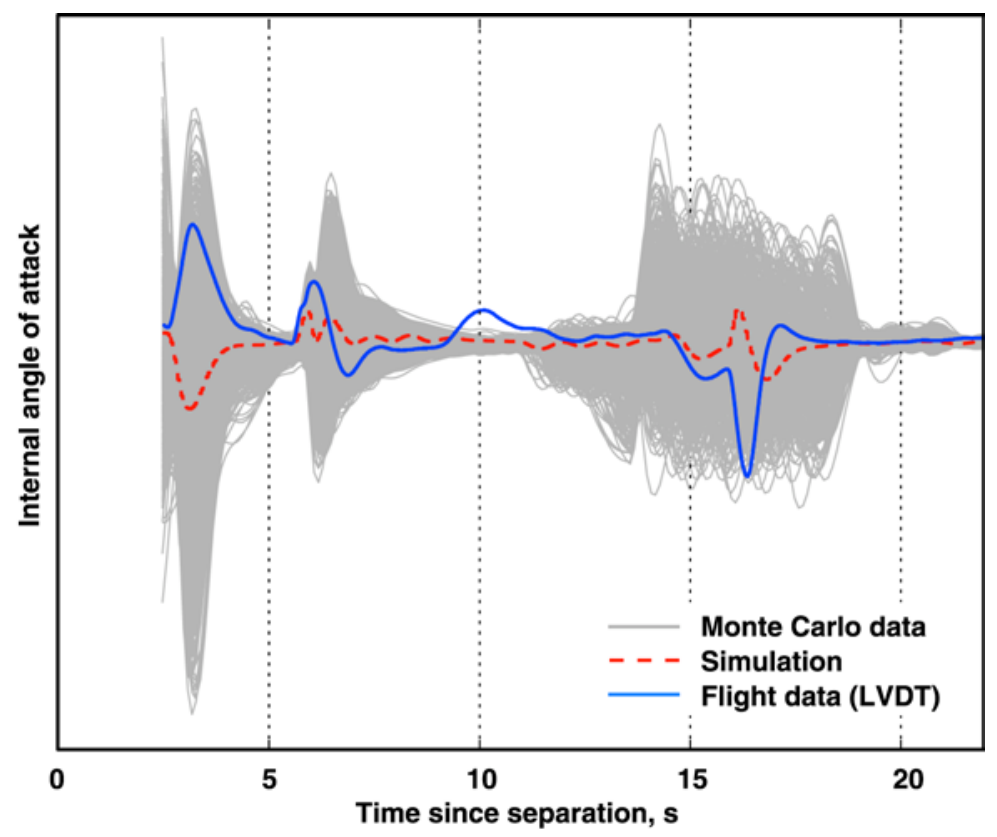

Figure 10. Engine test angle of attack. 


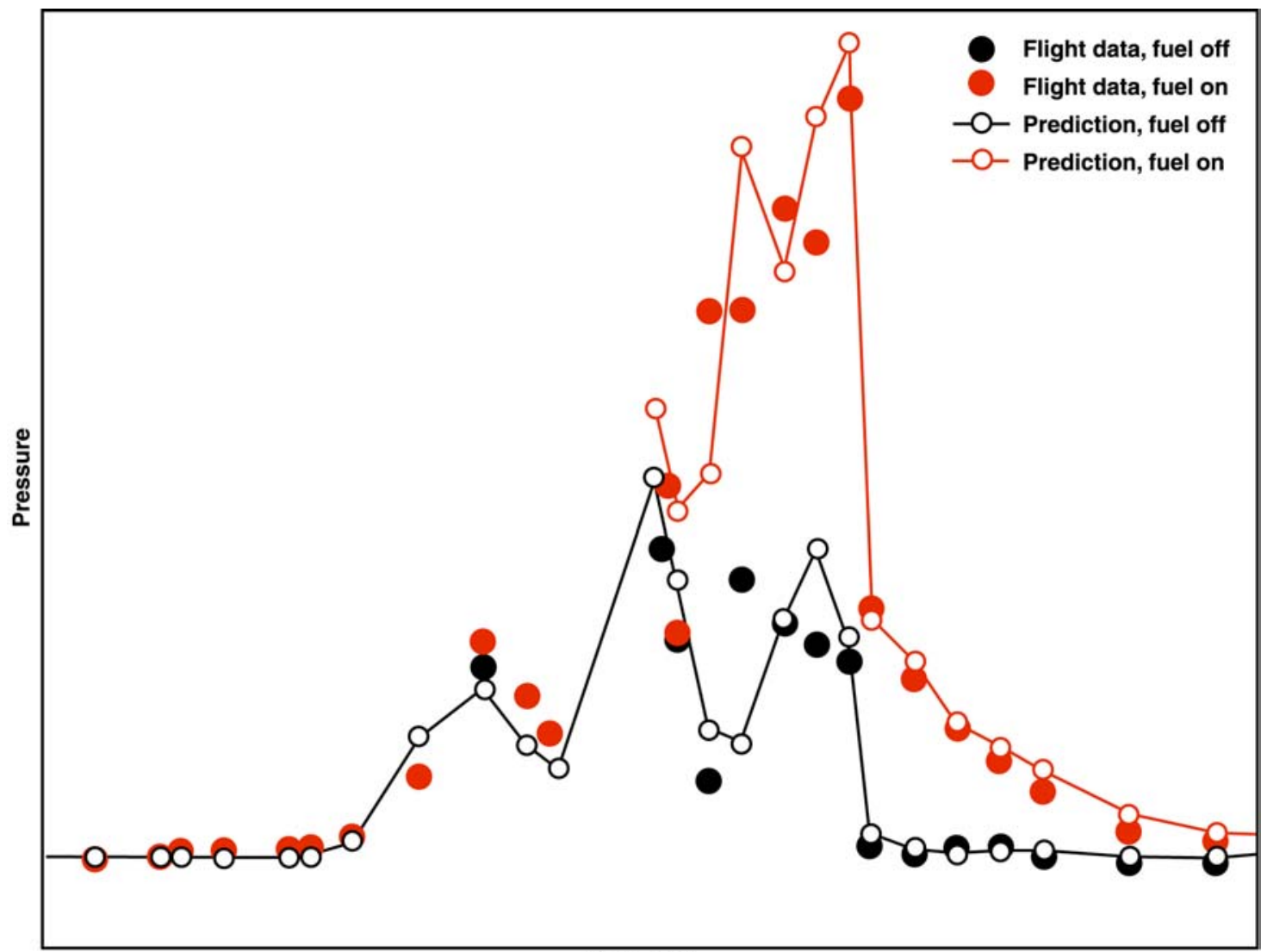

Axial station

Flow direction

Figure 11. Flight as a function of preflight propulsion database.

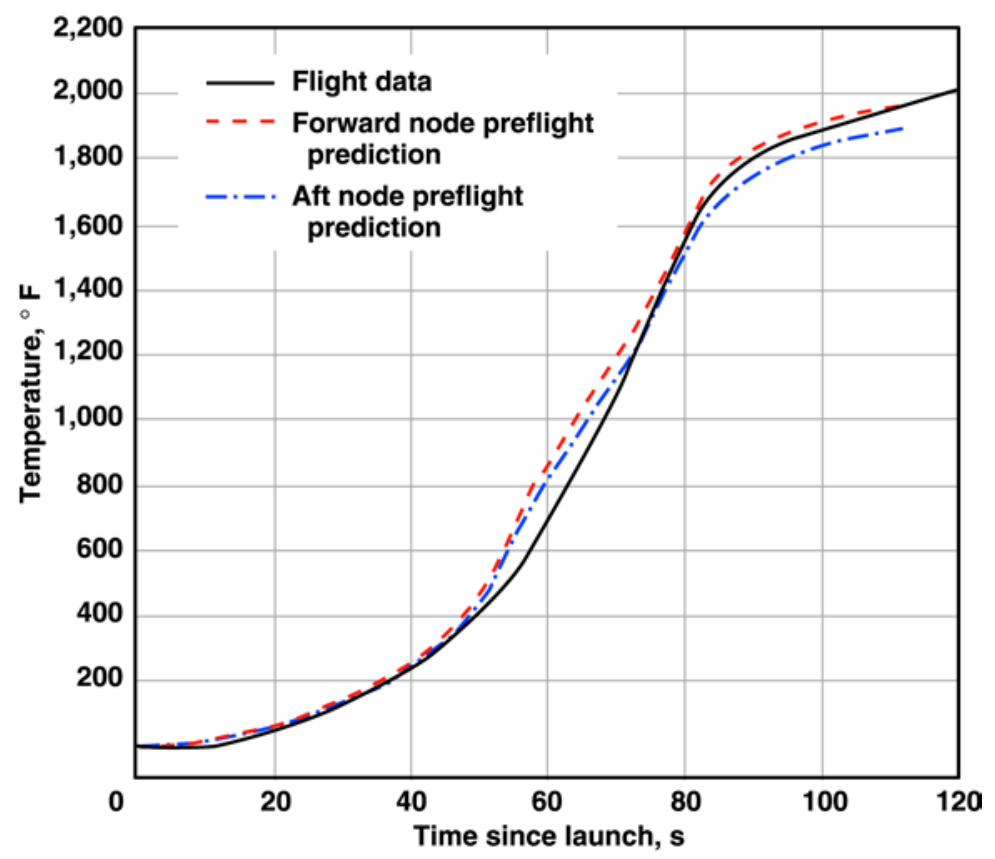

Figure 12. Nose temperature. 


\section{Descent}

The secondary portion of the mission began when the X-43A increased its angle of attack to initiate the recovery maneuver, beginning the descent. During the descent, the vehicle remained controlled and successfully completed all parameter identification maneuvers (PID). In general the actuators responded very well to the commands as shown in Fig. 13, which shows the surface positions and commands for both the rudders and the wings. The PID maneuvers are represented in these figures as the interval surface movements of all surfaces during the descent. The vehicle decelerated quickly, such that the seventh and final maneuver sequence performed began immediately after the sixth PID maneuver sequence was complete. Both the left rudder and left wing performed as expected throughout the flight; in spite of the contact incident they experienced preflight following the wing trim operation. The findings of the damage assessment team were consistent with the flight results; there were no apparent negative implications to the flight performance of either surface.

Also during the descent, the X-43A FMU inertial navigation system performed very well. Figures 14(a) and 14(b) show the system performance through comparison of free inertial navigation with GPS and blended navigation solutions for the descent. In all cases there was very good agreement. The discrepancy in Fig. 14(b) between the GPS and inertial east velocities was caused by a known range limit in the GPS velocity.

Vehicle data were acquired in the descent until a LOS when the X-43A was beyond the range of the P-3 aircraft. The LOS occurred 721 seconds after separation, approximately $600 \mathrm{nmi}(1,111 \mathrm{~km})$ from separation $(850 \mathrm{nmi}$ $(1,574 \mathrm{~km})$ from launch). At the time data were lost the X-43A was under control at an altitude of $918 \mathrm{ft}(279.8 \mathrm{~m})$, a Mach number of 0.72 , was approximately $4.5 \mathrm{nmi}(8.33 \mathrm{~km})$ from the aim point and well within the preflight predictions, as shown in Fig. 15.

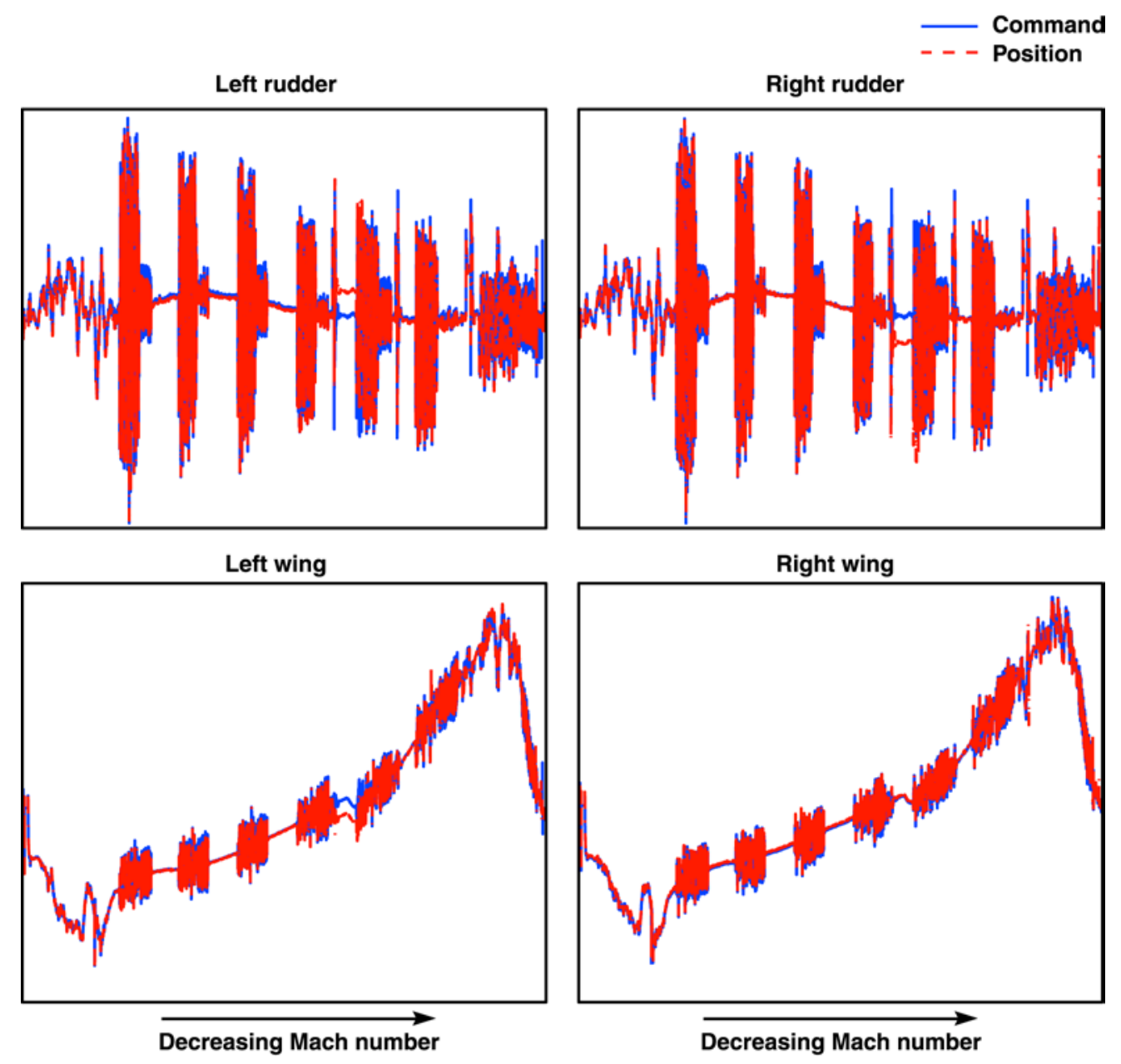

Figure 13. Control surfaces. 

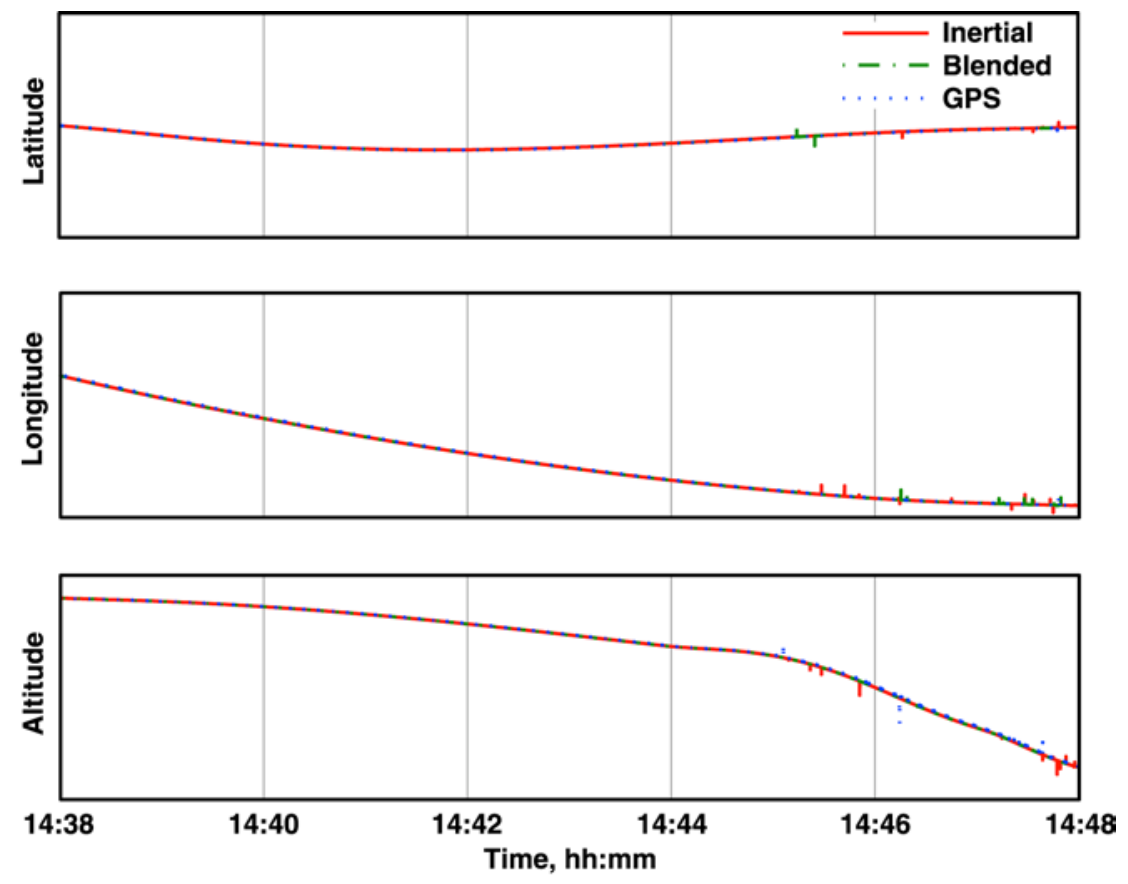

a) Vehicle positions.
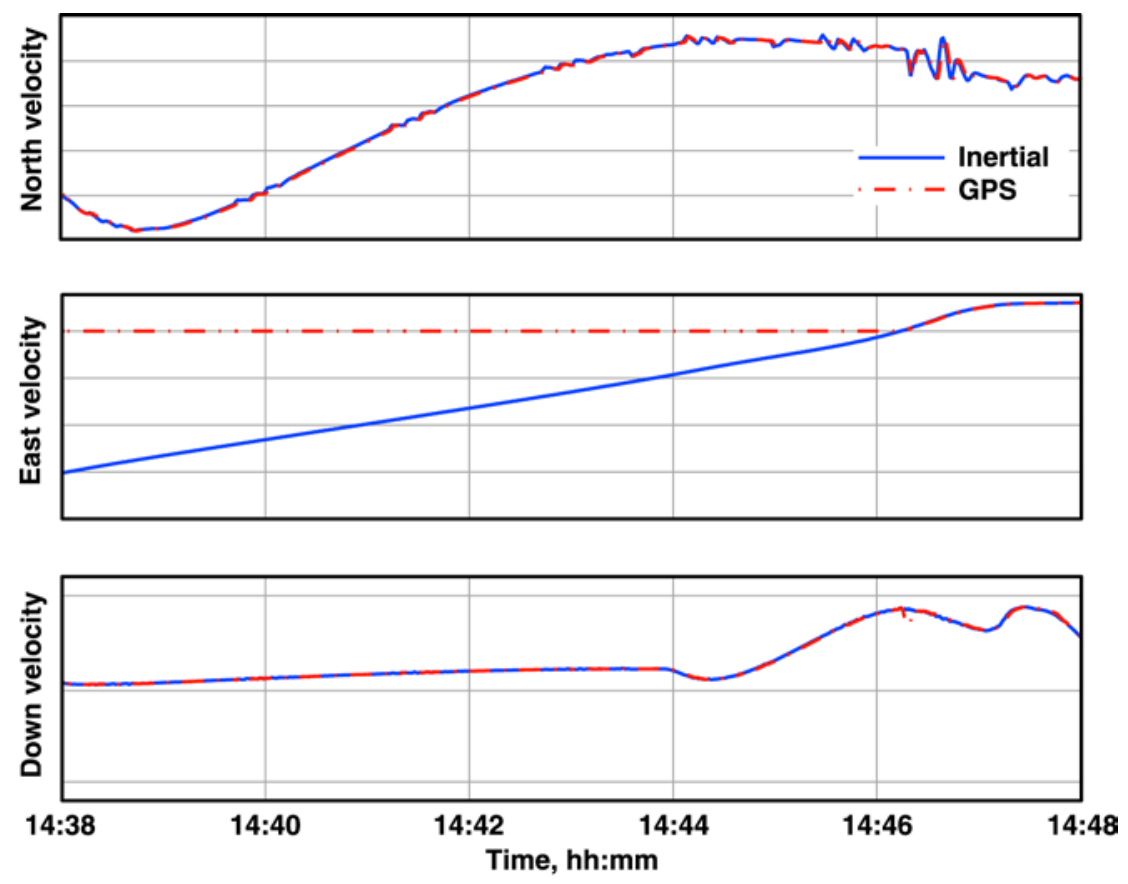

b) Vehicle velocities.

Figure 14. Descent inertial navigation performance. 


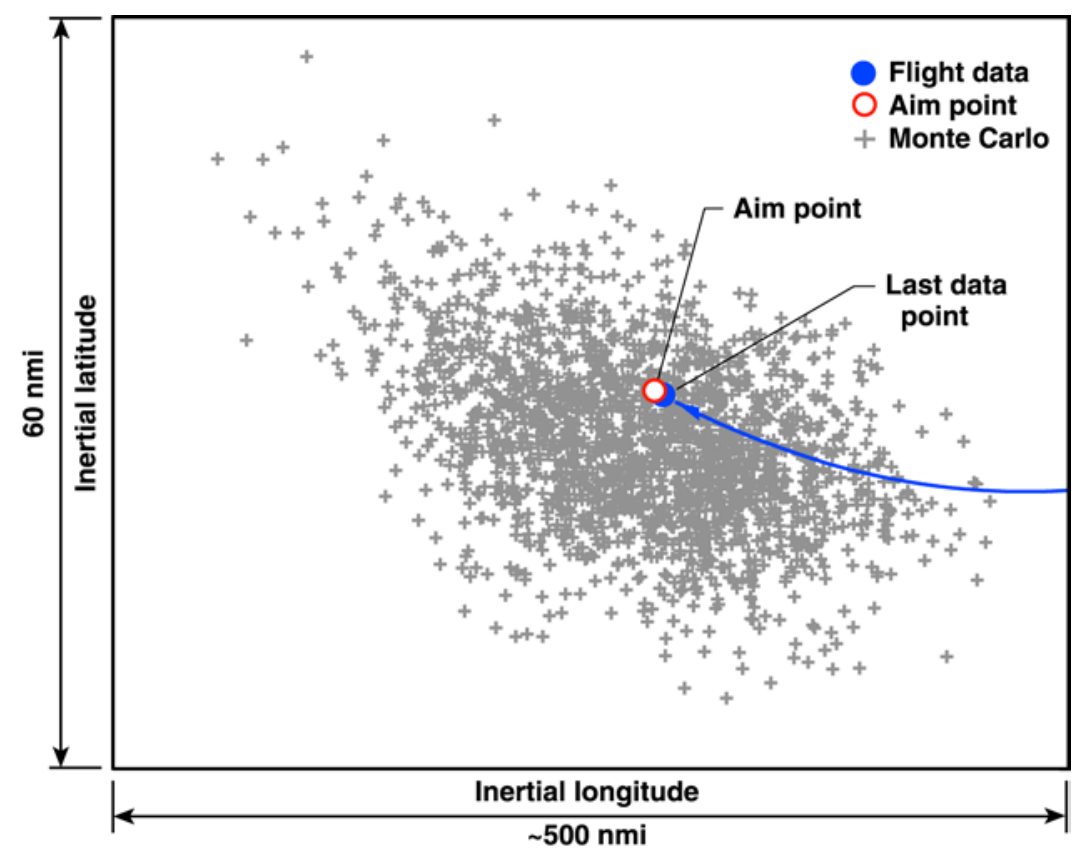

Figure 15. Descent performance, research vehicle last acquired data point.

\section{Significant Observations}

Even though the Mach $10 \mathrm{X}-43 \mathrm{~A}$ flight was very successful and accomplished all the primary mission objectives, there were some significant observations or anomalies that required additional analysis and study to understand how or why they occurred.

During the boost to the separation conditions telemetered data from the X-43A were lost in the control room for 13 seconds. The cause of the loss of signal was determined to be the manual operation of the best source selector, used to identify the telemetry asset with the best data during the mission. At the time of the X-43A data LOS, the Vandenberg Air Force Base 30-foot dish also experienced a loss of signal of this same duration. The best source selector should have been switched to another source for X-43A telemetered data. Data from all sources were available for post-flight analyses. Therefore, this issue only impacted the real-time data assessment during the boost.

Approximately 2 seconds prior to separation five of the RV adapter pressure sensors simultaneously indicated a loss of pressure. Of these five parameters, two were the port and starboard piston pressures. During the separation event, the indicated piston pressures were considerably lower than expected (Fig. 16). The peaks in the pressure curves shown in Fig. 16 are an artifact of where the sensor is located within the piston cylinder. Both pistons extended to a distance consistent with a nominal piston activation pressure and provided a successful separation. An examination of instrumentation schematics revealed that the five sensors that demonstrated the anomalous drop in pressure were all routed to a common signal-conditioning module. Since the piston extension versus time (Fig. 16) indicates that there was no physical drop in pressure and the affected parameters were all routed to a common module, the anomalous pressure drop occurrence was classified as an instrumentation anomaly.

During the 2.5 -second separation event, the X-43A took longer than predicted to arrive at the required engine test angle of attack (Fig. 17). This has most likely been attributed to a miscalculation of the pitching moment bias. During the flight 2 separation, the HXRV was also slow to arrive at the engine test conditions. ${ }^{3}$ As a result and to compensate for this occurrence, the flight 3 controller was modified to increase the angle of attack integrator gain. Although the estimated time for flight 3 to arrive at the test angle of attack was longer than predicted, the gain modification assisted in reducing that time such that the result was closer to the prediction than for flight 2 separation. ${ }^{6}$ 


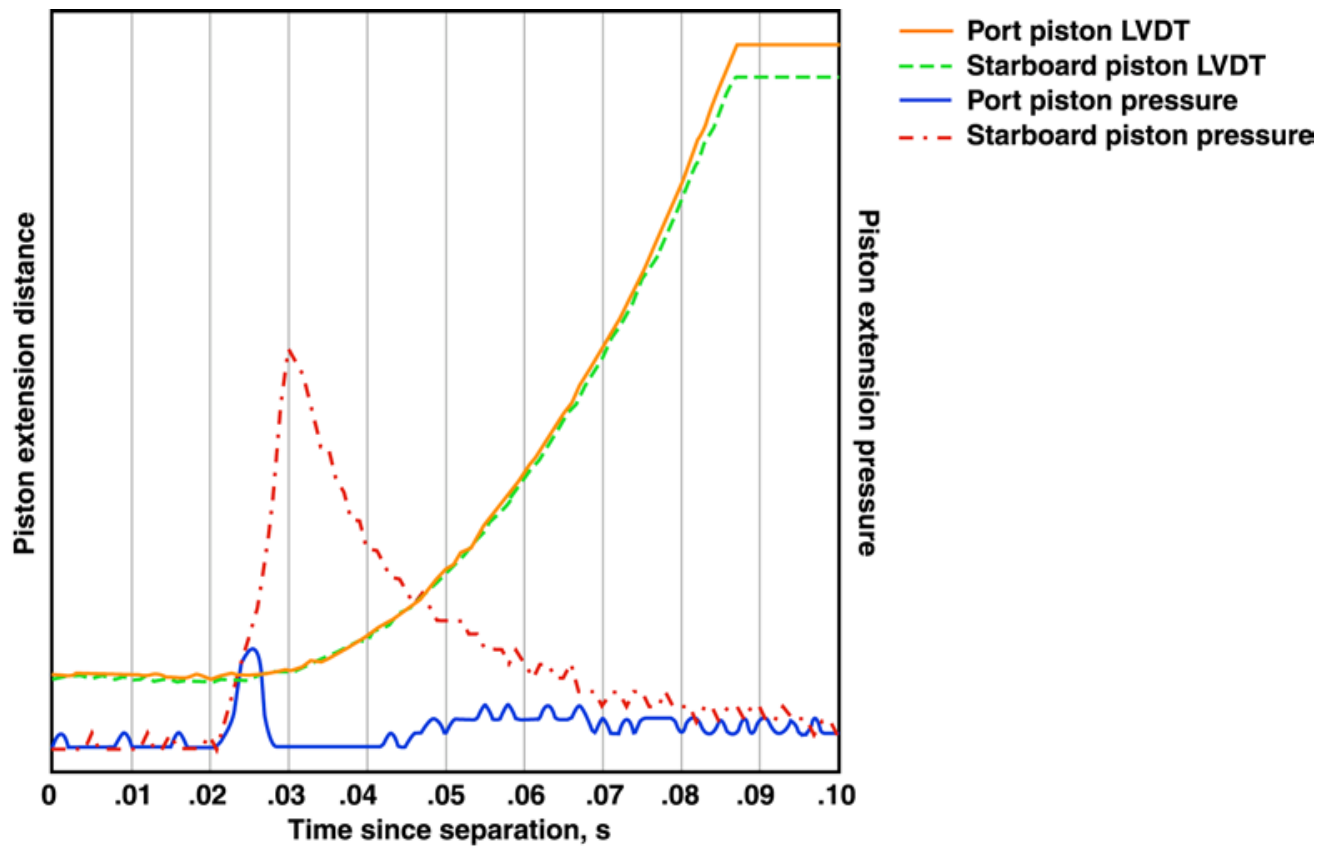

Figure 16. Piston extension and pressures.

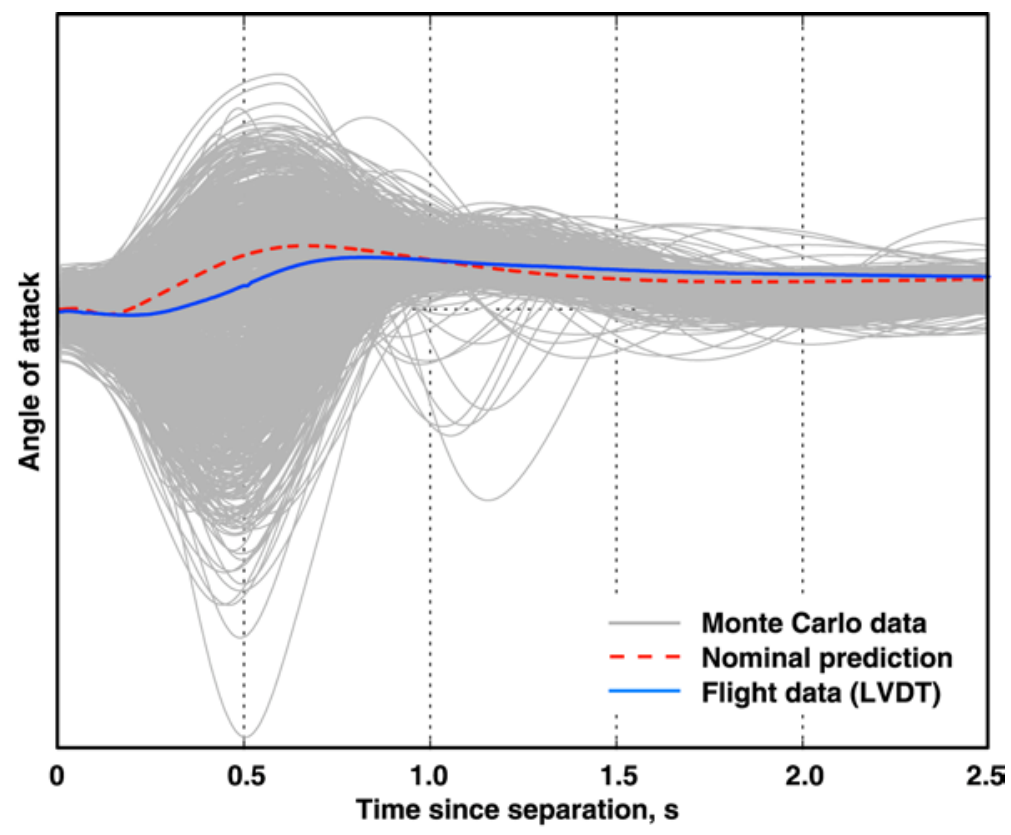

Figure 17. Separation angle of attack.

During the recovery maneuver, the X-43A began to oscillate in bank (Fig. 18(a)). At the same time that the oscillations began, pressures within the engine began to increase; these pressures had dropped as expected when the cowl door was closed following the engine experiment. The internal engine pressures were higher than the nominal cowl closed baseline data and indicate that air was flowing through the engine, which resulted in a vehicle nosedown attitude that the wings had to correct. Approximately 90 seconds after separation a large spike occurred in the wing position data in response to a disturbance (Fig. 18(a)). Since the silane vent began at approximately the same time (Fig. 18(b)), ignited silane gas in the engine is believed to be the cause of the disturbance. Comparisons of the roll 
oscillations (Fig. 18(a)), hydrogen and silane vent and purge (Fig. 18(b) $)^{5}$, and internal engine pressures show that the pressures dropped when the vent and purge was complete and the roll oscillations ceased. How air would be flowing through the engine during the descent has yet to be determined. The cowl door actuator data indicated that the door was closed following the engine experiment and remained so throughout the descent. The X-43A flew the remainder of the descent with no repeat of this incident; there is no known cause for either the initiation or cessation of this phenomenon.

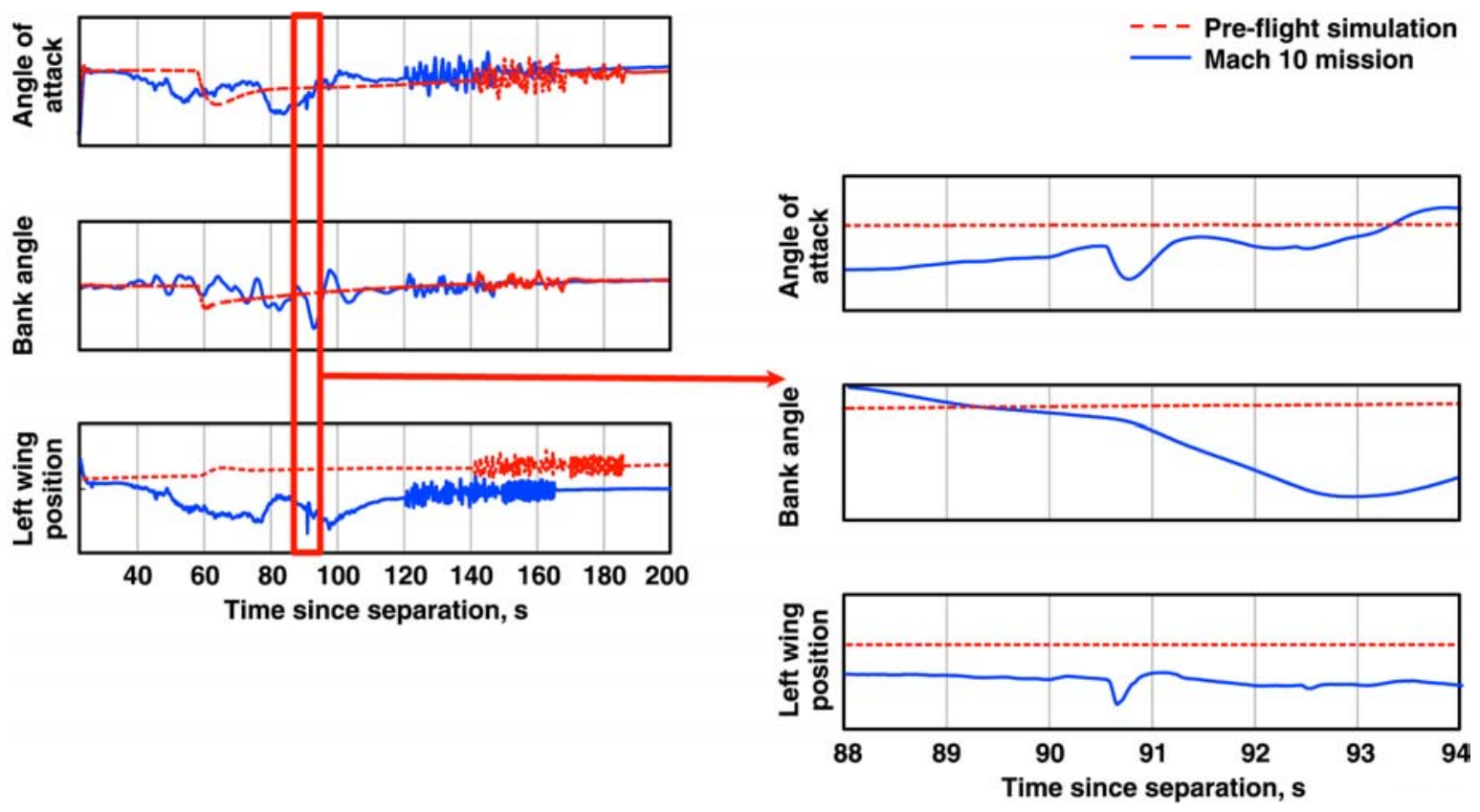

a) Post recovery maneuver.

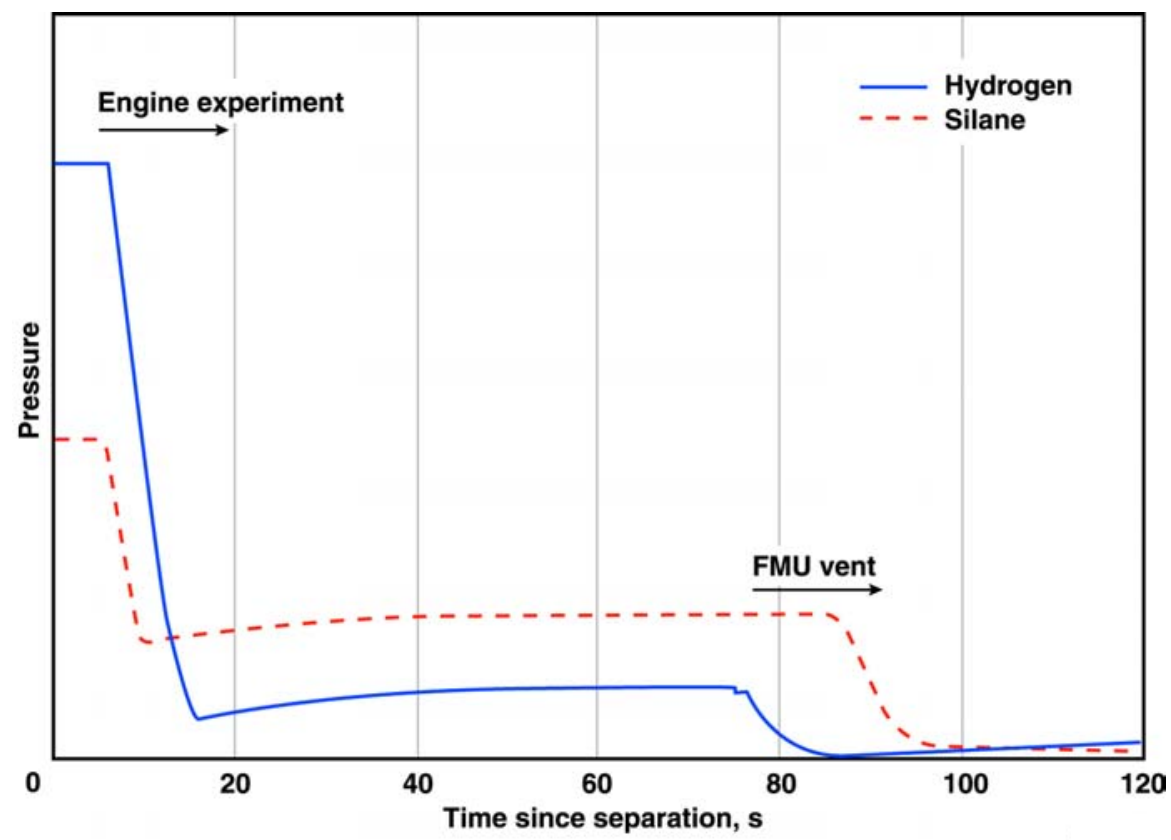

b) Fuel system vent and purge.

Figure 18. Descent anomaly. 
During the descent between the fourth and fifth PID maneuvers, a latched built-in test (LBIT) flag was set in the FMU, which indicated an allowable error limit had been exceeded. The problem was traced back to a spare channel. Since that channel was not connected to any system the allowable error limit had to have been exceeded by another channel on the same board. Of the six other channels on that board, five of them were related to control surface feedback and the sixth was an engine pressure channel. The engine pressure channel had exceeded the maximum input capability and the signal had bled over into the other channels on the board, which generated a bias on those channels. The bias was responsible for the LBIT flag as well as the 40 -second duration offset in left rudder, right rudder, and left wing, beginning at approximately 440 seconds after separation, seen in Fig. 19. Since the right wing channel was on a different board, it was unaffected by the bias (fig. 19). Actuation system performance was unaffected, since the bias was only applied to the feedback from the actuators, not the control surface position. The cause of the engine pressure exceeding limits and then returning to normal is unknown.
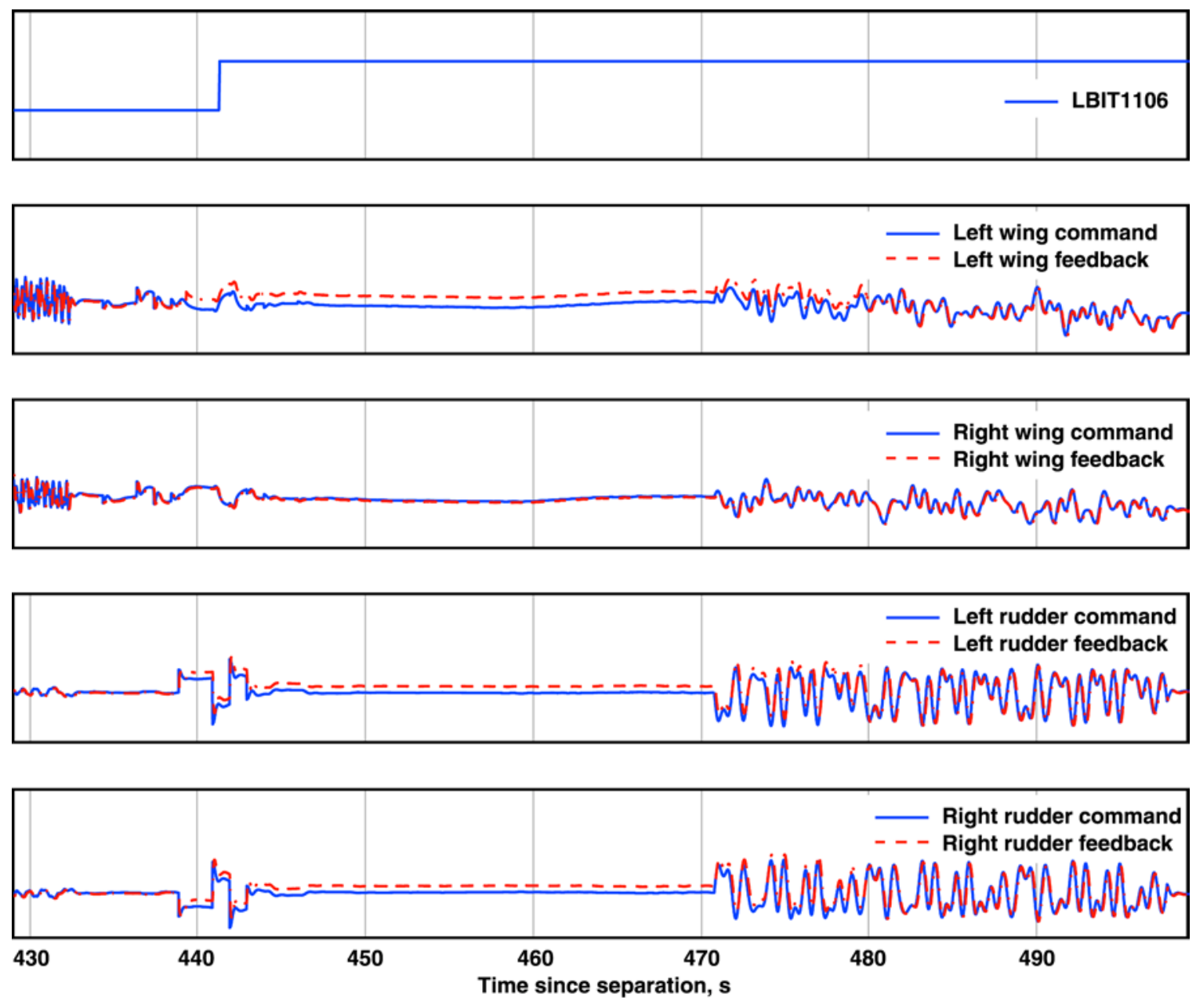

Figure 19. Descent LBIT flag set. 


\section{Lessons Learned}

The preparation for flight 3 encountered many challenges, some expected and some unexpected, from these, several lessons were learned and identified.

\section{A. Schedule Impact on Testing}

After flight 2 extended into 2004, it became clear that a more aggressive flight 3 schedule would be required. In an attempt to meet the schedule it might have become necessary to eliminate certain planned tests. Those tests that had been successfully performed in the past with predictable results were targeted for elimination. These tests included, aircraft in-the-loop (AIL) testing and X-43A compliance testing. The testing schedule for flight 3 benefited in three major ways. Some of the testing performed in support of flight 2 had been conducted using flight 3 hardware. Vehicle 2 tests had been performed recently and by many of the same people, such that vehicle 3 testing took less time than it did for vehicle 2 . So quickly in fact, that tests originally eliminated were put back into the test flow. Furthermore, the experience base with the test flow was so strong that tests were able to be resequenced to account for unforeseen delays in the schedule. Maintaining the core team allowed the schedule to be adhered to without sacrifices in testing.

\section{B. Decision to Not Incorporate Flight 2 Data Into the Flight 3 Models}

The decision to not incorporate flight 2 data analysis into the models was made in the interest of time and the ability to have flight software available to meet the flight schedule. The original program schedule allowed time for the flight 2 data analysis to be incorporated into flight 3 models. Although this was not the most desirable way to prepare for flight, the flight 2 data was used as guidance for updates and stress cases. The result was a controller that was able to handle the anomalous events encountered during the flight. If the flight 2 data analysis had been used to update the models directly, there might have been some improvements in X-43A performance. Even though all the primary mission and program objectives were met, it is important to remember that if the flight 2 data had been thoroughly analyzed and the results had been incorporated into the flight 3 models there might have been a better product. The knowledge base of the experienced team allowed for success where lack of sufficient analysis and incorporation could have been detrimental.

\section{Decision About P-3 Placement}

The flight conditions for the last acquired data point indicate that the X-43A was at an altitude of $918 \mathrm{ft}$ $(279.8 \mathrm{~m})$ and was descending at a rate of $228 \mathrm{ft} / \mathrm{s}(69.5 \mathrm{~m} / \mathrm{s})$. The parameter sample rates in the instrumentation system were such that more frames of data could have been obtained prior to splash if the vehicle had maintained the same rate of descent. At the time of LOS, the aim point was still $4.5 \mathrm{nmi}(8.33 \mathrm{~km})$ away, a result that may have been improved upon. However, capturing the engine test data was a primary mission objective, while capturing the descent was secondary. The P-3 placement decision was made using the primary mission objectives and concern for having a redundant good quality measurement for that portion of the mission. Although the ground-based assets were able to capture the engine test sequence for flight 2, the P-3 data was the best quality. This was true for flight 3 as well, which made the sacrifice of the descent data worthwhile. However advance scheduling with the P-3 maintenance schedule could have prevented the necessity of making such a decision in which case data from the entire mission, launch from B-52 to X-43A splash, could have been available.

\section{Carbon-Carbon Inspection During Manufacturing Process}

The late discovery of the carbon-carbon chine delamination during a final fit check could have eliminated the possibility of meeting the flight schedule. Only the availability of a spare billet that had already been through some of the heat treatment cycles prevented this from occurring. This event highlights the importance of spare pieces, but also indicates the necessity of in-process inspections. Non-invasive tap tests or thermographic inspections may increase costs, but the long duration manufacturing process warrants early identification of problems.

\section{E. HXRV Left-Rudder-Wing-Contact Incident Assessment}

The incident that occurred between the left rudder and left wing following the wing trim operation, was not caused by schedule pressure. If anything it was caused by performing a test in an off nominal way and without using a written procedure. Since the control surface had to be moved to perform the wing trim, a specific procedure should have been written and used to perform that action. 


\section{Concluding Remarks}

The third flight of the X-43A demonstrated that scramjets can work at flight conditions up to 9.68 Mach number and $109,000 \mathrm{ft}(33,223 \mathrm{~m})$ altitude. The X-43A project broadened the extent of the scramjet operational database and gave confidence that vehicles of this type could be designed and flown successfully. The data collected during the engine test is by far the largest amount of data acquired for a Mach 10 scramjet. The quantity, quality, and type of the data acquired is well beyond what has been acquired in wind tunnels. As with any major project some unforeseen events occurred in the preparation phase, these were handled well and lessons were learned from them. Although the primary objectives to demonstrate and validate the technology, the experimental techniques, and the design tools were met, some anomalous events occurred during the flight, which demonstrated the necessity for flight research. The successes of both this project and this flight are attributed to the processes for design, development, and testing, the dedicated project team and their strong expertise, and the teamwork between NASA, ATK GASL, Boeing, and Orbital Sciences Corporation.

\section{References}

${ }^{1}$ Freeman, D. C., Jr., Reubush, D.E.; McClinton, C. R., Rausch, V. L., and Crawford, J. L., The NASA Hyper-X Program, NASA TM-1997-207243, 1997.

${ }^{2}$ X-43A Mishap Investigation Board, Report of Findings X-43A Mishap, May 8, 2003. Online at www.nasa.gov/pdf/47414main_X43A_mishap.pdf

${ }^{3}$ Marshall, L. A., Corpening, G. P., and Sherrill, R., A Chief Engineer's View of the NASA X-43A Scramjet Flight Test, AIAA-2005-3332, Capua, Italy, May 13-20, 2005.

${ }^{4}$ Hunt, J. L., Eiswirth, E., A., NASA's Dual-Fuel Airbreathing Hypersonic Vehicle Study, AIAA-1996-4591, Norfolk, VA, November 18-22, 1996.

${ }^{5}$ Vachon, M. J., Grindle, T. J., St. John, C. W., and Dowdell, D. B., Fluid and Environmental Systems X-43A Flights 1, 2, and 3, AIAA-2005-3337, Capua, Italy, May 13-20, 2005.

${ }^{6}$ Baumann, E., Bahm, C., Beck, R., and Strovers, B., "The X-43A Mach 10 Mission Guidance and Control Updates, Rationale, and Flight Test Results." Presented at the Joint Army-Navy-NASA-Air Force (JANNAF) 40th Combustion (CS), $28^{\text {th }}$ Airbreathing Propulsion (APS), 22nd Propulsion Systems Hazards (PHSH), and 4th Modeling and Simulation (MSS) Joint Subcommittee Meeting, Charleston, South Carolina, June 13-17, 2005. 